\title{
Six newly sequenced chloroplast genomes from prasinophyte green algae provide insights into the relationships among prasinophyte lineages and the diversity of streamlined genome architecture in picoplanktonic species
}

\author{
Claude Lemieux*, Christian Otis and Monique Turmel
}

\begin{abstract}
Background: Because they represent the earliest divergences of the Chlorophyta, the morphologically diverse unicellular green algae making up the prasinophytes hold the key to understanding the nature of the first viridiplants and the evolutionary patterns that accompanied the radiation of chlorophytes. Nuclear-encoded 185 rDNA phylogenies unveiled nine prasinophyte clades (clades I through IX) but their branching order is still uncertain. We present here the newly sequenced chloroplast genomes of Nephroselmis astigmatica (clade III) and of five picoplanktonic species from clade VI (Prasinococcus sp. CCMP 1194, Prasinophyceae sp. MBIC 106222 and Prasinoderma coloniale) and clade VII (Picocystis salinarum and Prasinophyceae sp. CCMP 1205). These chloroplast DNAs (cpDNAs) were compared with those of the six previously sampled prasinophytes (clades I, II, III and V) in order to gain information both on the relationships among prasinophyte lineages and on chloroplast genome evolution.
\end{abstract}

Results: Varying from 64.3 to $85.6 \mathrm{~kb}$ in size and encoding 100 to 115 conserved genes, the cpDNAs of the newly investigated picoplanktonic species are substantially smaller than those observed for larger-size prasinophytes, are economically packed and contain a reduced gene content. Although the Nephroselmis and Picocystis cpDNAs feature a large inverted repeat encoding the rRNA operon, gene partitioning among the single copy regions is remarkably different. Unexpectedly, we found that all three species from clade VI (Prasinococcales) harbor chloroplast genes not previously documented for chlorophytes ( $n d h J, r b c R, r p l 21, r p s 15$, rps 16 and ycf66) and that Picocystis contains a trans-spliced group II intron. The phylogenies inferred from cpDNA-encoded proteins are essentially congruent with 185 rDNA trees, resolving with robust support all six examined prasinophyte lineages, with the exception of the Pycnococcaceae.

Conclusions: Our results underscore the high variability in genome architecture among prasinophyte lineages, highlighting the strong pressure to maintain a small and compact chloroplast genome in picoplanktonic species. The unique set of six chloroplast genes found in the Prasinococcales supports the ancestral status of this lineage within the prasinophytes. The widely diverging traits uncovered for the clade-VII members (Picocystis and Prasinophyceae sp. CCMP 1205) are consistent with their resolution as separate lineages in the chloroplast phylogeny.

Keywords: Viridiplantae, Prasinophytes, Prasinococcales, Picocystis, Picoplanktonic algae, Nephroselmis, Plastid genome, Phylogenomics, Genome reduction, trans-spliced group II intron

\footnotetext{
* Correspondence: claude.lemieux@bcm.ulaval.ca

Institut de biologie intégrative et des systèmes, Département de biochimie, de microbiologie et de bio-informatique, Université Laval, Québec, QC G1V OA6, Canada
} 


\section{Background}

Thriving mainly in marine environments, prasinophytes constitute an heterogeneous assemblage of unicellular green algae that occupy the earliest-diverging lineages of the Chlorophyta, i.e. the division of the Viridiplantae containing the bulk of extant green algae [1-3]. Sister to the Chlorophyta is the Streptophyta, which comprises freshwater green algae, the so-called charophytes, and all their land plant relatives. Given their basal positions, prasinophytes hold the key to understanding the nature of the last common ancestor of all green plants and the origin of the core chlorophytes (i.e. the Pedinophyceae, Chlorodendrophyceae, Trebouxiophyceae, Ulvophyceae and Chlorophyceae). The first green plants were undoubtedly unicellular algae bearing nonmineralized organic scales on their cell body and/or their flagella, because flagellated cells of many prasinophytes and streptophytes are covered by a layer of square-shaped scales [4]. Prasinophytes exhibit considerable diversity with respect to cell shape and size, flagella number and behavior, mitotic and cytokinetic mechanisms, and biochemical features such as accessory pigments and storage products [2,5-8]. They include the smallest free-living eukaryote known to date (Ostreococcus tauri with an average size of $0.8 \mu \mathrm{m}[9,10])$. Some prasinophytes lack flagella, others lack scales, and in some cases, both flagella and scales are absent (e.g., Ostreococcus).

Analyses of the nuclear-encoded small subunit (SSU) rRNA gene (18S rRNA gene) have identified nine monophyletic groups of prasinophytes, known as clades I through IX [11-14]. Most of these clades correspond to existing orders or classes; clades II, III and IV have recently been ranked at the class level (Mamiellophyceae [15], Nephroselmidophyceae [16] and Chlorodendrophyceae [17], respectively). Clades VIII and IX, the two most recently identified clades, are composed uniquely of environmental sequences [14]. The interrelationships between prasinophyte clades are still uncertain, considering that most of the internal branches separating these clades in $18 \mathrm{~S}$ rDNA trees received weak support values. Only for the class Chlorodendrophyceae (clade IV), which is nested within the core chlorophytes, is there confidence that it represents the latest divergence in the prasinophyte radiation. Six clades (clade II, clade V (Pycnococcaceae, Pseudocourfieldiales), clade VI (Prasinococcales), and clades VII through IX) display picoplanktonic species (i.e. organisms with a diameter of less than $3 \mu \mathrm{m}$ ), two of which (clades II and V) exhibit both the coccoid (no scales nor flagella) and flagellated cell organizations. It appears therefore that small-sized prasinophytes evolved multiple times from larger ancestors, presumably because selection favored smaller cells with less requirements per cell for nitrogen, phosphorus and other elements and a reduced tendency to be captured by filter-feeding predators [18].
Comparative analysis of chloroplast genomes has been helpful to resolve various issues concerning the relationships among green algal lineages [19-24]. To date, complete chloroplast genome sequences have been described for six prasinophytes that represent four distinct clades: clade I (Pyramimonadales), Pyramimonas parkeae [25]; clade II, Monomastix sp. OKE-1 [25], Micromonas sp. RCC 299 [26], and Ostreococcus tauri [27]; clade III, Nephroselmis olivacea [28]; and clade V, Pycnococcus provasolii [25]. These genomes display considerable fluidity in overall structure, gene content, and gene order. Whereas the 200-kb $N$. olivacea genome harbors the largest gene repertoire yet reported for a chlorophyte (128 different conserved genes compared with about 138 for the deepest branching streptophyte algae) and has retained many ancestral gene clusters, the genomes from the clade-II members belonging to the Mamiellales, which are the smallest $(\sim 72 \mathrm{~kb})$ and most compact chlorophyte chloroplast DNAs (cpDNAs) known to date, display a reduced set of genes (86 and 88 genes) whose order is highly scrambled. The 80-kb Pycnococcus and 114-kb Monomastix genomes (98 and 94 conserved genes, respectively) resemble their Ostreococcus and Micromonas homologs in featuring a reduced derived pattern of evolution, while the 102-kb Pyramimonas genome is more alike Nephroselmis cpDNA in harboring conserved genes unrecognized in other chlorophytes (rpl22 and $y c f 65)$ as well as a DNA primase gene putatively acquired from a virus. Like most of their chlorophyte and streptophyte counterparts, the N. olivacea, Pyramimonas and the two mamiellalean cpDNAs possess two identical copies of a large inverted repeat (IR) that are separated by single copy (SC) regions. The quadripartite architecture of the $N$. olivacea and Pyramimonas cpDNAs is ancestral (i.e. the $\mathrm{SC}$ regions are of vastly unequal size, each containing the highly conserved set of genes typically found in streptophyte cpDNAs, and the rRNA operon encoded by the IR is transcribed toward the small SC region), whereas the gene partitioning pattern observed for the two mamiellalean algae is highly derived.

Analysis of 70 concatenated chloroplast genes and encoded proteins from 24 taxa provided new insights into prasinophyte evolution even though the relationships among all prasinophyte clades could not be explored [25]. The inferred phylogenies disclosed a sister relationship between the Mamiellophyceae and Pyramimonadales and also offered compelling evidence that the green algal partner in the secondary endosymbiosis that gave rise to euglenids was a member of the Pyramimonadales. Consistent with this proposed sister relationship, the Mamiellophyceae and Pyramimonadales form a weakly supported clade in the ML tree reported by Nakayama et al. [29] on the basis of $18 \mathrm{~S}$ rDNA data; however, these two monophyletic groups are recovered as neighboring lineages in most published $18 \mathrm{~S}$ rDNA 
trees. The most important discordance between the chloroplast and 18S rDNA trees concerns the position of Nephroselmis: the branch occupied by this genus represents the earliest divergence in chloroplast trees but is part of a later-diverging group of prasinophytes (clades III, $\mathrm{V}$ and VII) in $18 \mathrm{~S}$ rDNA trees. Remarkable differences in the branching order of prasinophyte lineages were also observed between 18S rDNA trees and a phylogeny of 47 green plants inferred from complete cpDNA-encoded rRNA operon sequences lineages [15]. The nodes separating most major prasinophyte lineages in the latter chloroplast phylogeny received weak levels of support.

In the present investigation, we have sequenced the chloroplast genomes of five picoplanktonic prasinophytes belonging to two clades that have not been previously sampled for chloroplast genome analysis, clades VI (Prasinococcales) and clade VII. We have also examined the cpDNA of Nephroselmis astigmatica, a clade-III member representing a lineage distinct from Nephroselmis olivacea (see [15,29]). These genome sequences were compared with those of previously examined prasinophytes in order to gain more information on the relationships among prasinophyte lineages and on chloroplast genome evolution. Our phylogenomic analyses revealed that the branching order observed for the six examined prasinophyte clades is largely congruent with previously reported $18 \mathrm{~S}$ rDNA trees $[12,15]$ but in contrast to the latter trees, most internal nodes received robust support. The genomes of all the newly investigated picoplanktonic prasinophytes are economically packed and substantially smaller than those observed for prasinophytes with larger cell size, further confirming the notion that small cells have small genomes. Unexpectedly, we found that the three picoplanktonic species occupying the deepest branch (i.e. belonging to the Prasinococcales) harbor several chloroplast genes not previously documented for chlorophytes.

\section{Results and discussion}

The six prasinophyte chloroplast genomes sequenced in the course of this study differ extensively from one another at several levels. Their gene maps are shown in Figures 1, 2 and 3 and their structural features are compared with those previously observed for six other prasinophytes in Table 1. The newly investigated cpDNAs of picoplanktonic species belonging to clades VI and VII vary in size from 64,335 (in Prasinophyceae sp. CCMP 1205, clade VII) to 85,590 bp (in Prasinococcus, clade VI), encode between 100 (in Prasinophyceae sp. CCMP 1205) and 115 genes (in Prasinococcus) that are densely packed, and with the exception of the Picocystis cpDNA (clade VII), contain no IR encoding the rRNA operon. The representative of clade III, Nephroselmis astigmatica, exhibits a larger and more gene-rich genome that encodes 123 genes and displays an ancestral quadripartite structure. At the level of gene content, important differences were found within and between clades (Figure 4). Although pairwise genome comparisons revealed that numerous genes form conserved clusters (Figures 1, 2 and 3), gene order is substantially scrambled in all three sampled lineages and multiple ancestral clusters are disrupted in clades VI and VII (Figure 5).

Because an accurate phylogenetic framework is essential to track the suite of cpDNA changes that took place during prasinophyte evolution, we will present our phylogenomic analyses of concatenated cpDNA-encoded proteins before elaborating further on the structural features of the newly sequenced prasinophyte genomes.

\section{The phylogenies inferred from cpDNA-encoded proteins are essentially congruent with the branching order of prasinophyte clades in $18 \mathrm{~S}$ rDNA trees}

A data set of 14,382 unambiguously aligned positions was assembled from 71 cpDNA-encoded proteins of 32 chlorophytes and 15 streptophytes, the streptophyte sequences being used as outgroup. Amino acid sequences rather than nucleotide sequences were chosen for our phylogenomic analyses because, in analyses of ancient divergences, amino acid data sets are less prone than nucleotide data sets to saturation problems, convergent compositional biases and convergent codon-usage biases [30-32]. The amino acid data set of 14,382 positions was first analyzed using PhyloBayes and the site-heterogeneous CATGTR $+\Gamma 4$ model of amino acid substitutions. This model is known to provide a better fit than site-homogeneous models, thus minimizing the impact of systematic errors stemming from the difficulties to detect and interpret multiple substitutions [33-36]. The majority-rule consensus tree resolved six independent lineages for the 12 sampled prasinophytes (Figure 6). We observed with high bootstrap proportion (BP) and posterior probability (PP) support that the three picoplanktonic species belonging to clade VI (i.e. the Prasinococcales) occupies the earliest branch of the Chlorophyta and that the representatives of clades I and II (Pyramimonadales + Mamiellophyceae) form a clade representing the second deepest divergence. As expected, the two Nephroselmis species are allied (clade III), forming the third deepest branch of the tree, a branch also robustly supported. The next divergence is represented by the clade-V member, Pycnococcus; the relative position of this lineage is uncertain as it received the lowest BP support (only 63\%). The two remaining prasinophytes, Picocystis and Prasinophyceae sp. CCMP 1205, which have both been assigned to clade VII, form separate and robustly supported lineages, with the latest diverging lineage being occupied by Prasinophyceae sp. CCMP 1205. The latter lineage is sister to a $100 \%$ BP supported clade containing the Ulvophyceae, Trebouxiophyceae and Chlorophyceae (UTC clade) and of these classes, only the Chlorophyceae is resolved as a strongly supported 


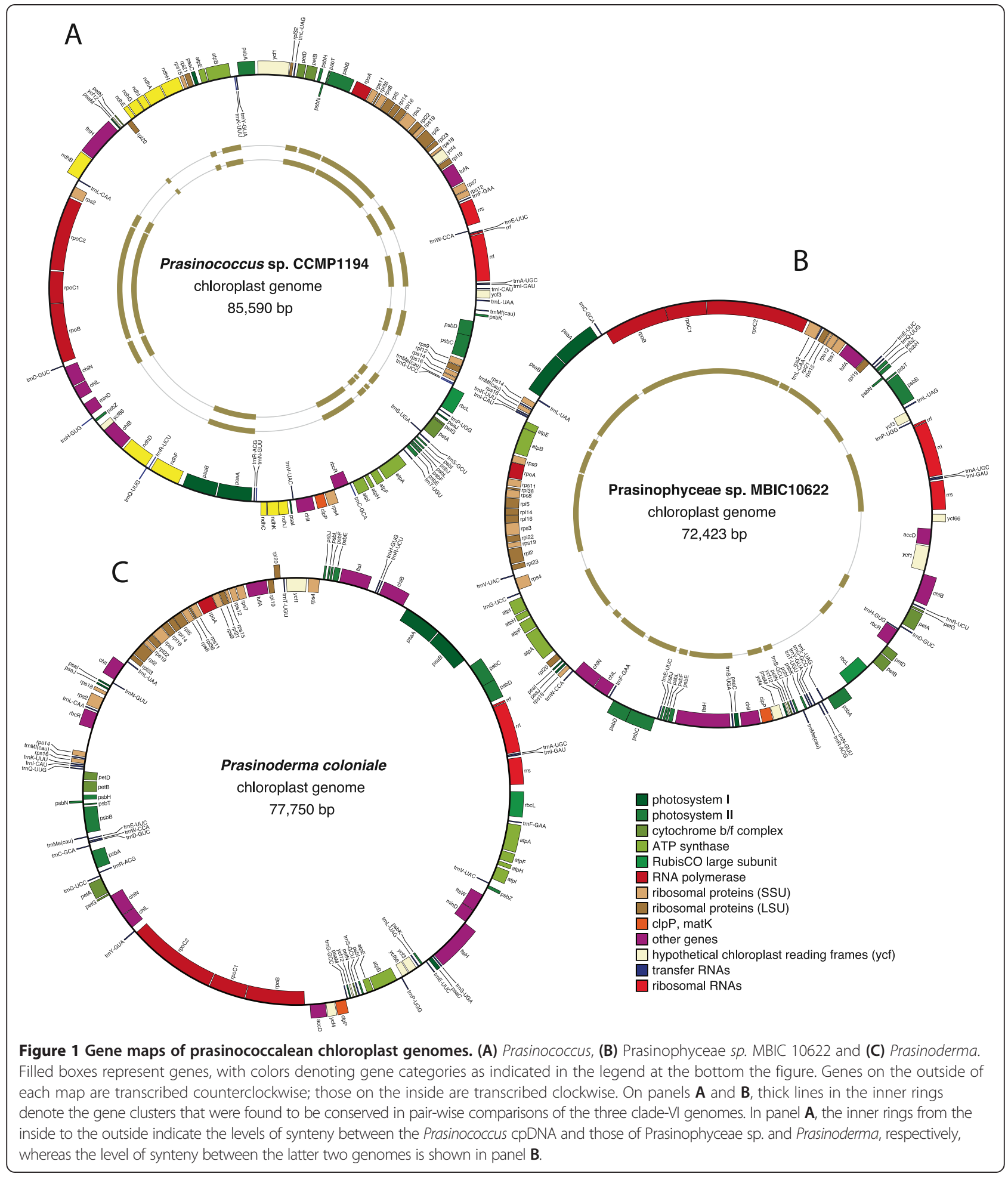

monophyletic group. Even though the branching order of lineages within the UTC clade is in agreement with a previous chloroplast phylogenomic study [37], this topology might not reflect the true organismal relationships as taxon sampling is sparse (see [38]).
The amino acid data set of 14,382 positions was also analyzed using RAxML under the gcpREV $+\Gamma 4$ and LG4X models, with each model applied to the data set partitioned by gene. LG4X is a mixture model based on four substitution matrices [39], whereas gcpREV is an empirical 


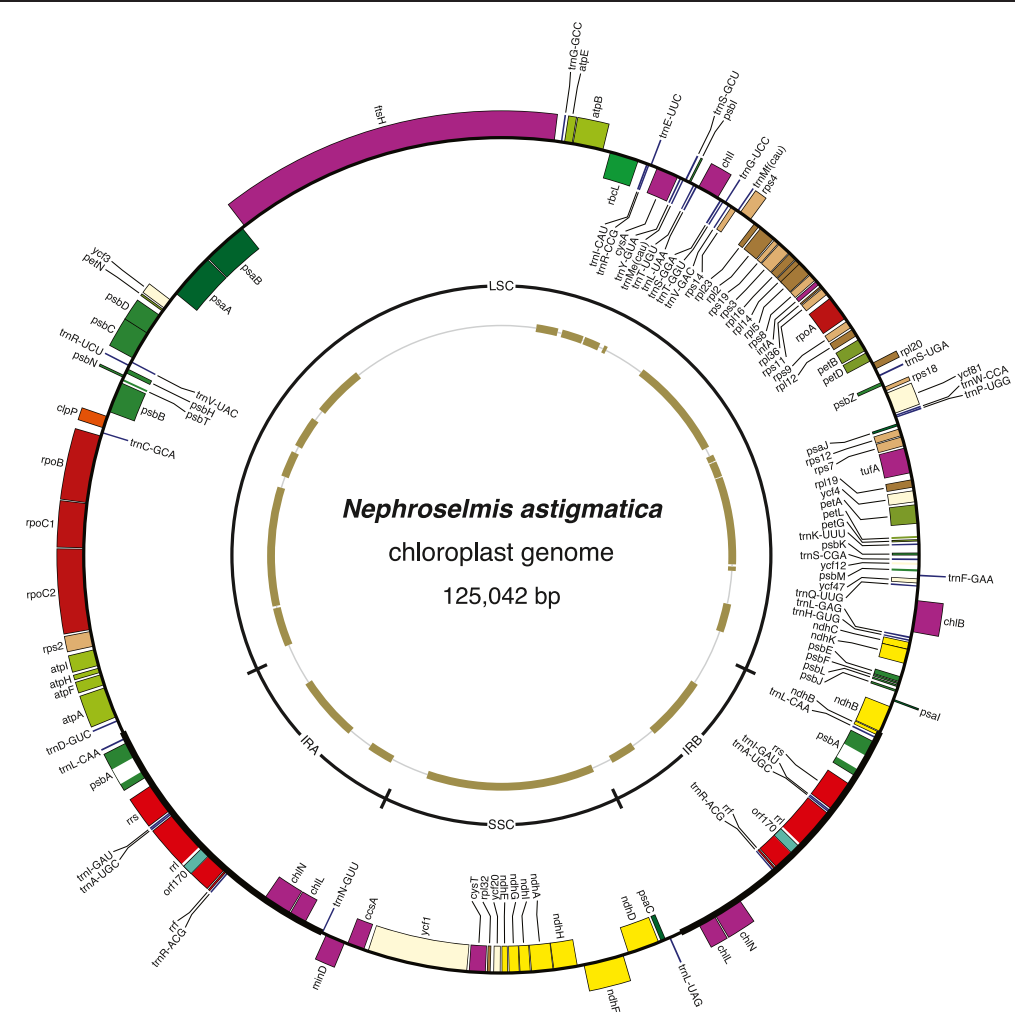

Figure 2 Gene map of the Nephroselmis astigmatica choroplast genome. Filled boxes represent genes, with colors denoting categories as indicated in Figure 1. Genes on the outside of the map are transcribed counterclockwise; those on the inside are transcribed clockwise. The outermost inner ring indicates the positions of the IR and SC regions. Thick lines in the innermost ring represent the conserved gene clusters between Nephroselmis astigmatica and Nephroselmis olivacea cpDNAs.

model derived from green plant chloroplast sequences [40]. The recovered trees were found to be essentially congruent with the Bayesian tree obtained under CATGTR + $\Gamma 4$; however, the interrelationships between the prasinophyte lineages were weakly to moderately supported (Figure 6). Indeed, all prasinophyte lineages, except the Prasinophyceae sp. CCMP 1205, received BP support lower than $72 \%$. Given this result, we asked whether ML trees inferred from an amino acid data set with a larger number of characters (15,549 positions) could provide better support for the relationships among prasinophyte lineages. This second data set was assembled from 79 cpDNA-encoded proteins of 32 chlorophytes and two streptophytes, and trees were inferred using PyloBayes under the CATGTR $+\Gamma 4$ model and RAxML under GTR $+\Gamma 4$, LG4X, and gcpREV $+\Gamma 4$ (Figure 7). In all phylogenies, the branching order of prasinophyte lineages was identical to that shown in Figure 6, and higher BP support values were observed for the positions of the early-diverging prasinophytes lineages (clade VI, clades I + II and clade III) as compared to the ML analyses of the original amino acid data set.

Systematic errors are common in phylogenetic studies not only when taxon sampling is sparse but also when some of the taxa produce long branches [36]; indeed, these long branches tend to associate erroneously with those of other taxa showing high sequence divergence, yielding the long-branch artifact [41]. In this context, we note that three of the four prasinophyte lineages occupied by picoplanktonic species, i.e. Prasinococcales, Pycnococcus and Prasinophyceae sp. CCMP 1205, display longer branches than the other prasinophyte lineages. It is unlikely, however, that the branching order reported here for prasinophyte lineages was hampered by the long-branch attraction phenomenon because the phylogenies we inferred using various models, including the heterogeneous model of evolution CATGTR $+\Gamma 4$, are essentially identical and that their topology is congruent with the branching order of major prasinophyte lineages in nuclear-encoded SSU trees $[12,15,29]$. Furthermore, it seems improbable that the prasinophyte relationships resolved in our study were affected by convergent compositional biases and convergent codon-usage biases because we found that the reported amino acid-based phylogenies are congruent with the RAxML tree inferred from a fully degenerated nucleotide data set obtained by substituting the nucleotides with ambiguity codes that allow for all possible synonymous changes (data not shown). 


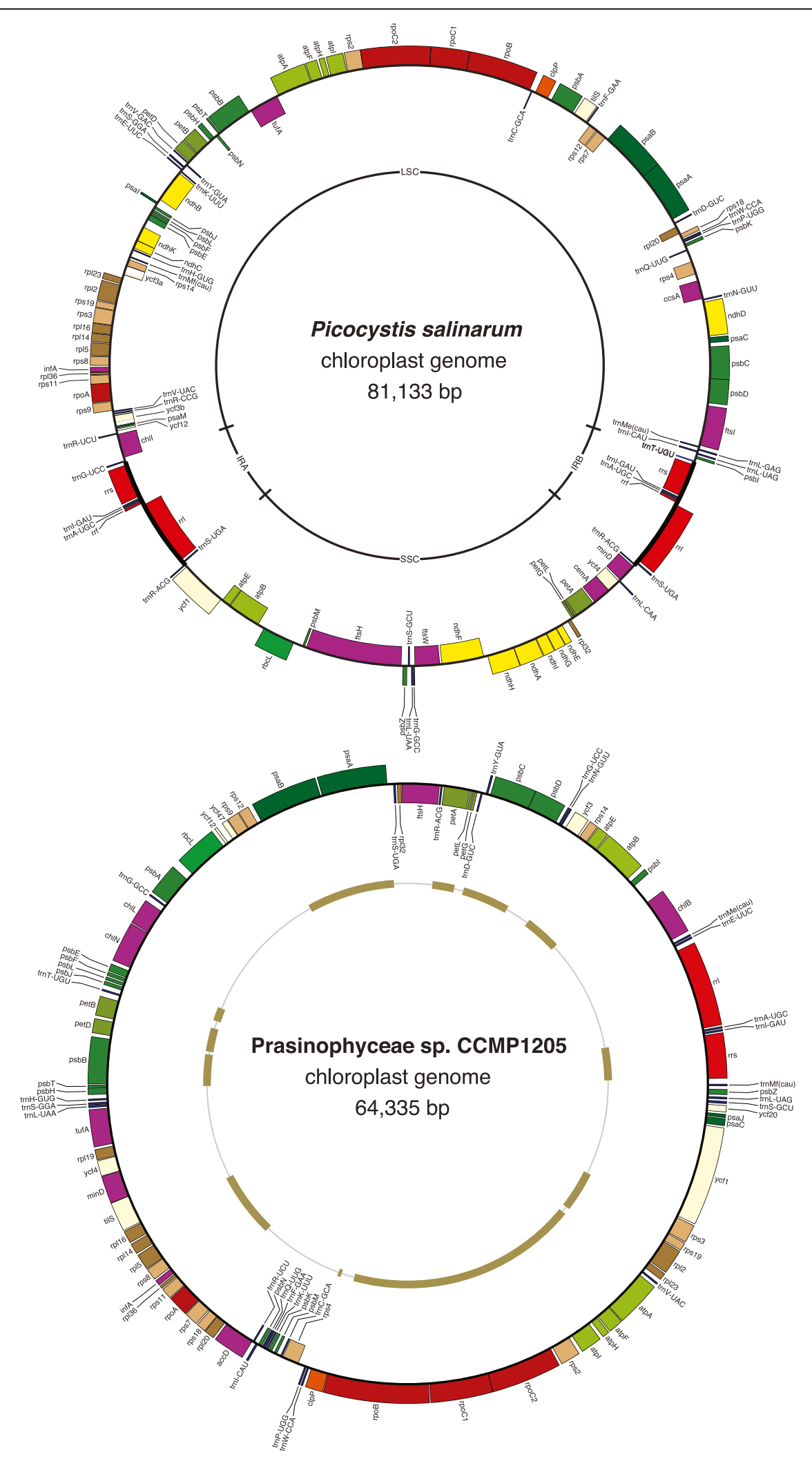

Figure 3 (See legend on next page.) 
(See figure on previous page.)

Figure 3 Gene maps of the Picocystis salinarum and Prasinophyceae sp. CCMP 1205 chloroplast genomes. Filled boxes represent genes, with colors denoting categories as indicated in Figure 1. Genes on the outside of each map are transcribed counterclockwise; those on the inside are transcribed clockwise. The intron sequences bordering the Picocystis ycf3 exons (ycf3a and ycf3b) are spliced in trans at the RNA level. The IR and SC regions of the Picocystis genome are represented on the inner ring. The gene clusters shared by the Picocystis and Prasinophyceae sp. CCMP 1205 genomes are displayed on the ring inside the gene map of the latter genome.

Our chloroplast phylogenomic trees differ from phylogenies based on $18 \mathrm{~S}$ rDNA data by the sister relationship identified for the Pyramimonadales and Mamiellophyceae $[12,15]$, the positioning of the Pycnococcaceae after the emergence of the Nephroselmidophyceae [12,15,29] and the finding that the two representatives of clade VII are not allied [12,15,29]. In the $18 \mathrm{~S}$ rDNA trees reported by Guillou et al. [12] and Marin and Melkonian [15], the Pyramimondales diverge before the Mamiellophyceae but support for this earlier divergence is very low. Considering that the branch leading to Pycnococcus (Pycnococcaceae) received weak support in both the chloroplast and $18 \mathrm{~S}$ rDNA trees, the differences related to the relative position of this lineage are also not unexpected. Note here that $18 \mathrm{~S}$ rDNA trees either resolve the Pycnococcaceae as an earlier divergence compared to the Nephroselmidophyceae [15,29] or group these two lineages in a poorly supported clade [12]. Likewise, in light of the weak support observed for clade VII in $18 \mathrm{~S}$ rDNA trees as well as in the analysis of the chloroplast rDNA operon by Marin and Melkonian [15], resolution of Picocystis (clade VIIC in [12]) and Prasinophyceae sp. CCMP 1205 (clade VIIA in [12]) as neighboring lineages in our phylogenomic analyses does not necessarily represent an inconsistency.

Considering that the prasinophyte clades IV, VIII and IX were not sampled in our study, a number of other issues could not be addressed concerning the interrelationships between the major prasinophyte clades. Representatives of clade IV (Chlorodendrophyceae) would be expected to affiliate to the core chlorophytes (i.e.

Table 1 General features of the prasinophyte cpDNAs compared in this study

\begin{tabular}{|c|c|c|c|c|c|c|c|c|c|}
\hline \multirow{2}{*}{$\begin{array}{l}\text { Taxon } \\
\text { Name }\end{array}$} & \multirow[b]{2}{*}{ Label } & \multicolumn{2}{|l|}{ Size } & \multirow[b]{2}{*}{$A+T(\%)$} & \multirow[b]{2}{*}{ Genes $^{a}$} & \multicolumn{2}{|c|}{ Introns ${ }^{b}$} & \multirow[b]{2}{*}{ Intergenic ${ }^{c}(\%)$} & \multirow[b]{2}{*}{ Repeats $^{d}(\%)$} \\
\hline & & Total (bp) & IR (bp) & & & GI & GII & & \\
\hline \multicolumn{10}{|l|}{ Clade VI } \\
\hline Prasinococcus sp. CCMP 1194 & PCUS & 85,590 & & 67.9 & 115 & & & 14.3 & 0.9 \\
\hline Prasinophyceae sp. MBIC 106222 & $\mathrm{MBIC}$ & 72,423 & & 62.1 & 103 & & & 13.4 & 1.1 \\
\hline Prasinoderma coloniale CCMP 1220 & PRMA & 77,750 & & 65.9 & 106 & & & 16.0 & 0.4 \\
\hline \multicolumn{10}{|l|}{ Clade I } \\
\hline Pyramimonas parkeae CCMP 726 & PYRA & 101,605 & 13,057 & 65.3 & 110 & & 1 & 22.4 & 0.5 \\
\hline \multicolumn{10}{|l|}{ Clade II } \\
\hline Micromonas sp. RCC 299 & MICR & 72,585 & 7,307 & 61.2 & $86^{e}$ & & & 19.0 & 0 \\
\hline Monomastix sp. OKE-1 & MONO & 114,528 & & 61.0 & 94 & 5 & 1 & 44.6 & 16.9 \\
\hline Ostreococcus tauri & OSTR & 71,666 & 6,824 & 60.1 & 88 & & 1 & 15.1 & 0 \\
\hline \multicolumn{10}{|l|}{ Clade III } \\
\hline Nephroselmis astigmatica NIES 252 & NAST & 125,042 & 13,742 & 59.5 & 123 & 2 & & 18.6 & 0.3 \\
\hline Nephroselmis olivacea NIES 484 & NOLI & 200,801 & 46,137 & 57.9 & $128^{f}$ & & & 45.6 & 0.5 \\
\hline \multicolumn{10}{|l|}{ Clade V } \\
\hline Pycnococcus provasolii CCMP 1203 & PYCN & 80,211 & & 60.5 & $99^{9}$ & & 1 & 14.0 & 0 \\
\hline \multicolumn{10}{|l|}{ Clade VII } \\
\hline Picocystis salinarum CCMP 1897 & $\mathrm{PICO}$ & 81,133 & 10,364 & 62.7 & 114 & & 1 & 9.2 & 0 \\
\hline Prasinophyceae sp. CCMP 1205 & 1205 & 64,335 & & 63.3 & 100 & & & 10.0 & 0 \\
\hline
\end{tabular}

${ }^{\mathrm{a}}$ Duplicated genes were counted only once.

${ }^{b}$ Number of group I (GI) and group II (GII) introns is given.

'Only the ORFs coding for proteins of known functions or having recognized domains were considered as genes.

${ }^{\mathrm{d}}$ Nonoverlapping repeat elements were mapped on each genome with RepeatMasker [70] using the repeats $\geq 30$ bp identified with REPuter [69] as input sequences.

${ }^{\mathrm{e}}$ This value is probably an underestimate because the genome sequence appears to be incomplete and missing three genes (see the legend of Figure 4).

${ }^{\mathrm{f}}$ The ycf20 pseudogene, which corresponds to the annotated orf111, was not counted.

${ }^{9}$ This value differs from that reported previously [25] because an additional gene, rrf (coordinates 33313-33429 in [GenBank:NC_012097]), was identified using RNAmmer [64] in the course of this study. 


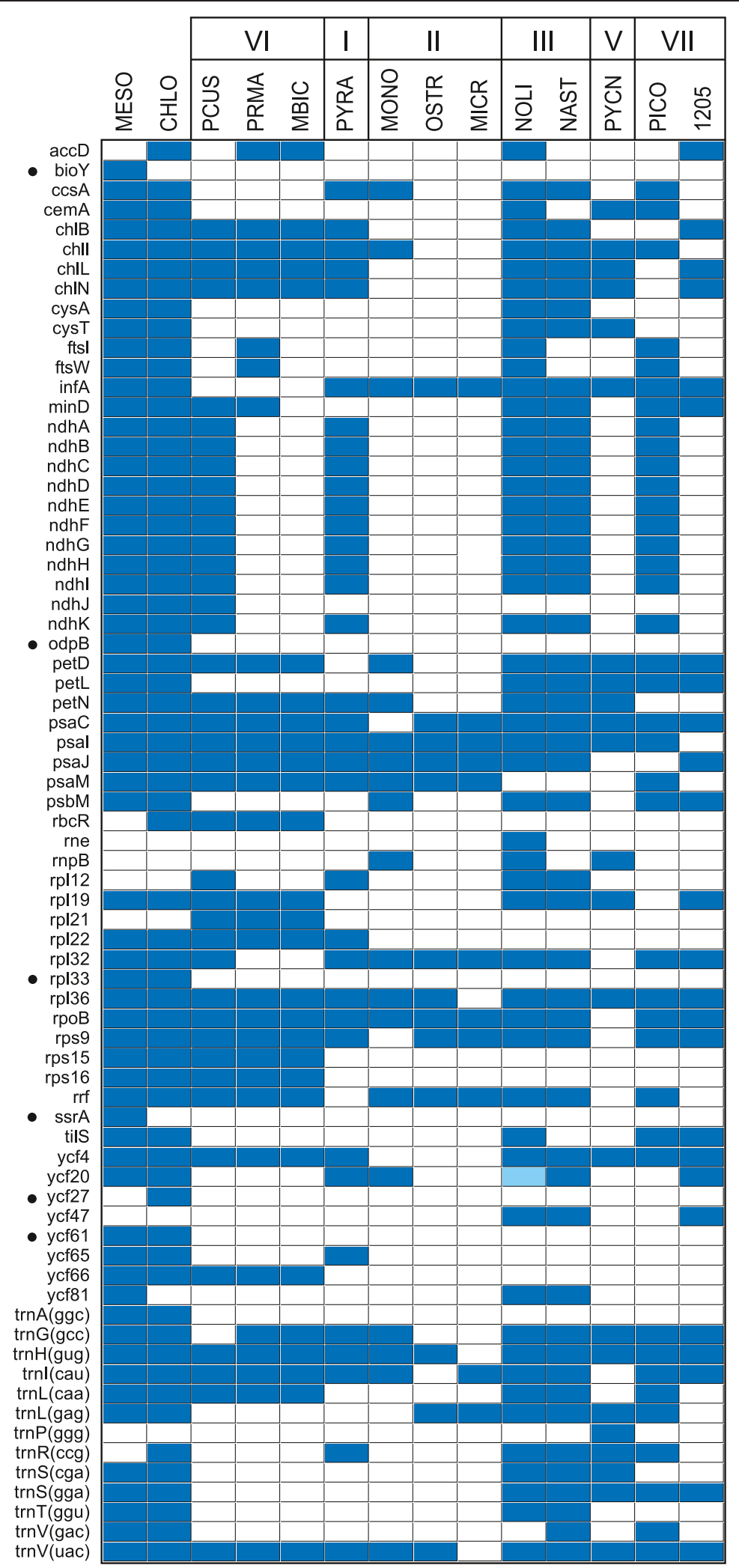

Figure 4 (See legend on next page.) 
(See figure on previous page.)

Figure 4 Differences between the chloroplast gene repertoires displayed by prasinophytes and the deep-branching streptophytes Mesostigma viride and Chlorokybus atmophyticus. The conserved genes missing in one or more prasinophyte genome as well as the six conserved genes found in Mesostigma and/or Chlorokybus but absent from all prasinophytes are indicated in the figure; the streptophyte-specific genes are denoted by filled circles. The presence of a gene is indicated by a dark blue box and the presence of a pseudogene by a light blue box. Species names are abbreviated as in Table 1. Although rp/36, trnH (gug) and trnV (uac)) are recorded as missing in Micromonas, all three genes are probably present because three lines of evidence suggest that the genome sequence in the [GenBank:NC_012575] accession is partial and that a missing segment contains these genes: 1) the three genes are conserved in all other compared green algae, 2) given that chloroplast gene order is colinear in Ostreococcus and Micromonas, they are predicted to be contiguous and located between psbB and trnG (ucc) 3) these predicted positions correspond to the circularization endpoints of the genome assembly deposited in [GenBank:NC_012575]. Species names for prasinophytes are abbreviated as in Table 1 . A total of 75 genes are shared by all compared prasinophyte $c \mathrm{pDNAs:}$ atpA, $B, E, F, H, I, c l p P, f t s H, p e t A$, B, G, psaA, B, psbA, B, C, D, E, F, H, I, J, K, L, N, T, Z, rbcL, rpl2, 5, 14, 16, 20, 23, rpoA, C1, C2, rps2, 3, 4, 7, 8, 11, 12, 14, 18, 19, rrl, rrs, tufA, ycf1, 3, 12, trnA (ugc), C (gca), D (guc), E (uuc), F (gaa), G (ucc), I (gau), K (uuu), L (uaa), L (uag), Me (cau), Mf (cau), N (guu), P (ugg), Q (uug), R (acg), R (ucu), S (gcu), $S$ (uga), $T$ (ugu), $W$ (cca) and $Y$ (gua).

the clade containing the Pedinophyceae, Trebouxiophyceae, Ulvophyceae and Chlorophyceae), although the exact position of clade IV within this group is still unclear. Concerning the clades VIII and IX, which were defined uniquely by environmental $18 \mathrm{~S}$ rDNA sequences, sampling of these groups will await the availability of algal cultures in public collections. Because these clades appear to be loosely affiliated with the Nephroselmidophyceae and Pycnococcaceae, respectively [14], analyses of chloroplast genomes from representative species would be very helpful to resolve the position of the Pycnococcaceae.

\section{The small, IR-less cpDNAs of the clade-VI picoalgae (Prasinococcales) feature six genes not previously documented in chlorophytes}

The small sizes of the three examined prasinococcalean chloroplast genomes $(72.4$ to $85.6 \mathrm{~kb})$ are accounted for by losses of genes and of the IR, tight packaging of the retained genes and the absence of introns (Table 1 and Figure 4). With 103 to 115 genes, Prasinococcus, Prasinoderma, and Prasinophyceae sp. MBIC 106222 have lost numerous genes compared to Nephroselmis olivacea (128 genes) but not as many as the tiny prasinophytes from clades II and V (86 to 98 genes). Most importantly, these prasinococcaleans have retained six genes that have not been previously identified in other chlorophytes: $n d h J, r b c R, r p l 21, r p s 15, r p s 16$, and $y c f 66$ (Figure 4). Some of these picoalgae also feature genes that were reported only in the chloroplast of Nephroselmis olivacea (ftsI and ftsW) or Pyramimonas (rpl22). Of the three prasinococcaleans examined, the earliestdiverging taxon (i.e. Prasinococcus, see Figure 6) displays the largest gene repertoire. Its 115 genes include the genes encoding all 11 subunits homologous to the mitochondrial NADH:ubiquinone oxidoreductase ( $n d h$ genes), whereas the cpDNAs of Prasinoderma and Prasinophyceae sp. MBIC 10622 are entirely lacking these genes. Furthermore, it is worth mentioning that the $\operatorname{trn} E$ (uuc) gene coding for glutamyl-tRNA, which is a crucial RNA component not only for protein synthesis but also for chlorophyll synthesis [42], is duplicated in the chloroplasts of Prasinoderma and Prasinophyceae sp. MBIC 10622. Duplication of trnE (uuc) also occurred prior to the divergence of the Chlamydomonadales and Sphaeropleales (Chlorophyceae) [19,43]; however, whether the acquisition of the extra gene copy conferred a biological advantage is still unknown. Note that another tRNA gene, trnL (uag), is duplicated in Prasinophyceae sp. MBIC 10622.

The set of six chloroplast genes found in the Prasinococcales but missing in all other chlorophyte clades provides independent support for the ancestral status of the Prasinococcales within the prasinophyte lineages. This is because positioning of the Prasinococcales as the first branch of the Chlorophyta, rather than as a later divergence, yields the most parsimonious scenario of losses for these six genes, all of which, except $n d h J$, are predicted to have been lost only once. According to this scenario, $n d h J$ sustained loss not only just after the emergence of the Prasinococcales but also in the lineage leading to the Prasinophyceae sp. MBIC 10622.

In terms of gene order, the Prasinoderma and Prasinophyceae sp. MBIC 10622 cpDNAs more closely resemble each other (the 19 shared gene clusters include $67 \%$ of the Prasinoderma and 69\% of the Prasinophyceae genes) than do the Prasinococcus cpDNA and each of the former genomes (the 17 and 16 shared clusters include $55 \%$ of the Prasinoderma and 54\% of the Prasinophyceae genes) (Figures 1A and B). Most of the chloroplast gene clusters that are usually shared between streptophytes and chlorophytes have been preserved in prasinococcaleans (Figure 5); one notable exception is the rRNA operon which has been fractured between rrs (SSU rRNA gene) and trnI (cau) in Prasinococcus. The newly identified rps15, rps16 and $n d h J$ genes reside in the same gene context as their streptophyte counterparts and some of the missing genes (infA, petL, cysT and $o d p B$ ) appear to have been cleanly excised from ancestral gene clusters. 


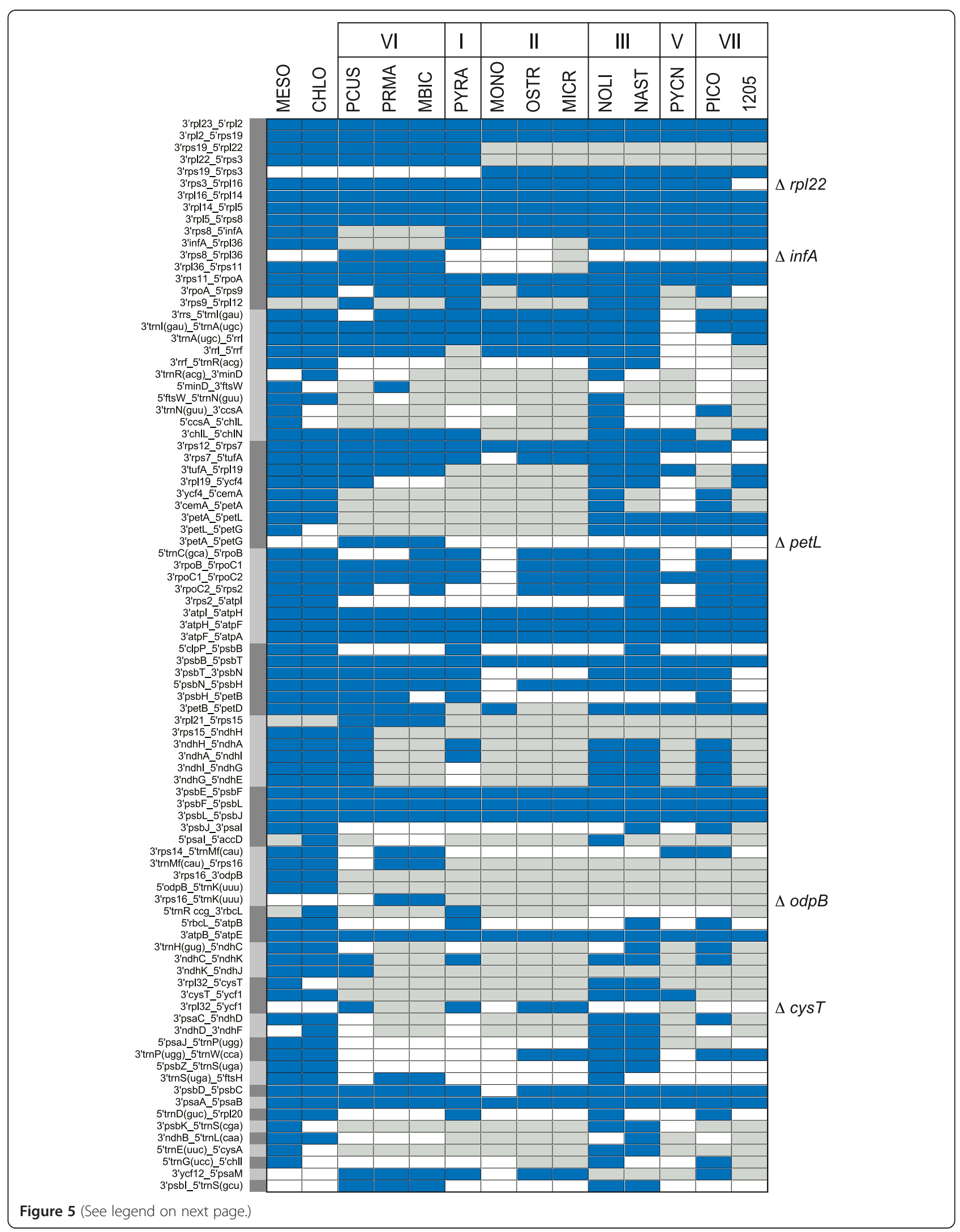


(See figure on previous page.)

Figure 5 Distribution of ancestral gene pairs among the 12 prasinophyte cpDNAs examined in this study. We selected all the gene pairs that are shared by at least two prasinophytes from distinct lineages and also by one or both of the streptophytes Mesostigma and Chlorokybus. In addition, when one of the genes in a given gene pair was missing from several prasinophyte lineages or from the two streptophytes, gene pairs conserved in a single prasinophyte lineage or missing from streptophytes were selected. The presence of a gene pair is denoted by a dark blue box; a gray box indicates that at least one gene is missing due to gene loss. The gene pairs forming larger conserved clusters are grouped and individual genes that were cleanly deleted from some of these clusters are indicated on the right of the figure. Species names are abbreviated as in Table 1.

\section{The ancestral quadripartite structure of Nephroselmis} astigmatica cpDNA features an IR three-fold smaller than its $N$. olivacea homolog

Prior to this study, the IR-containing chloroplast genome of Nephroselmis olivacea (Nephroselmidophyceae, clade III) was known to be the prasinophyte cpDNA with the most ancestral pattern of evolution. Its main attributes include a quadripartite structure very similar to those of the streptophyte algae Mesostigma [44] and Chlorokybus [22], a large gene repertoire, and an ancestral gene organization [28]. The impressive size of its IR (46,136 bp), however, represents an unusual feature. Although it carries several

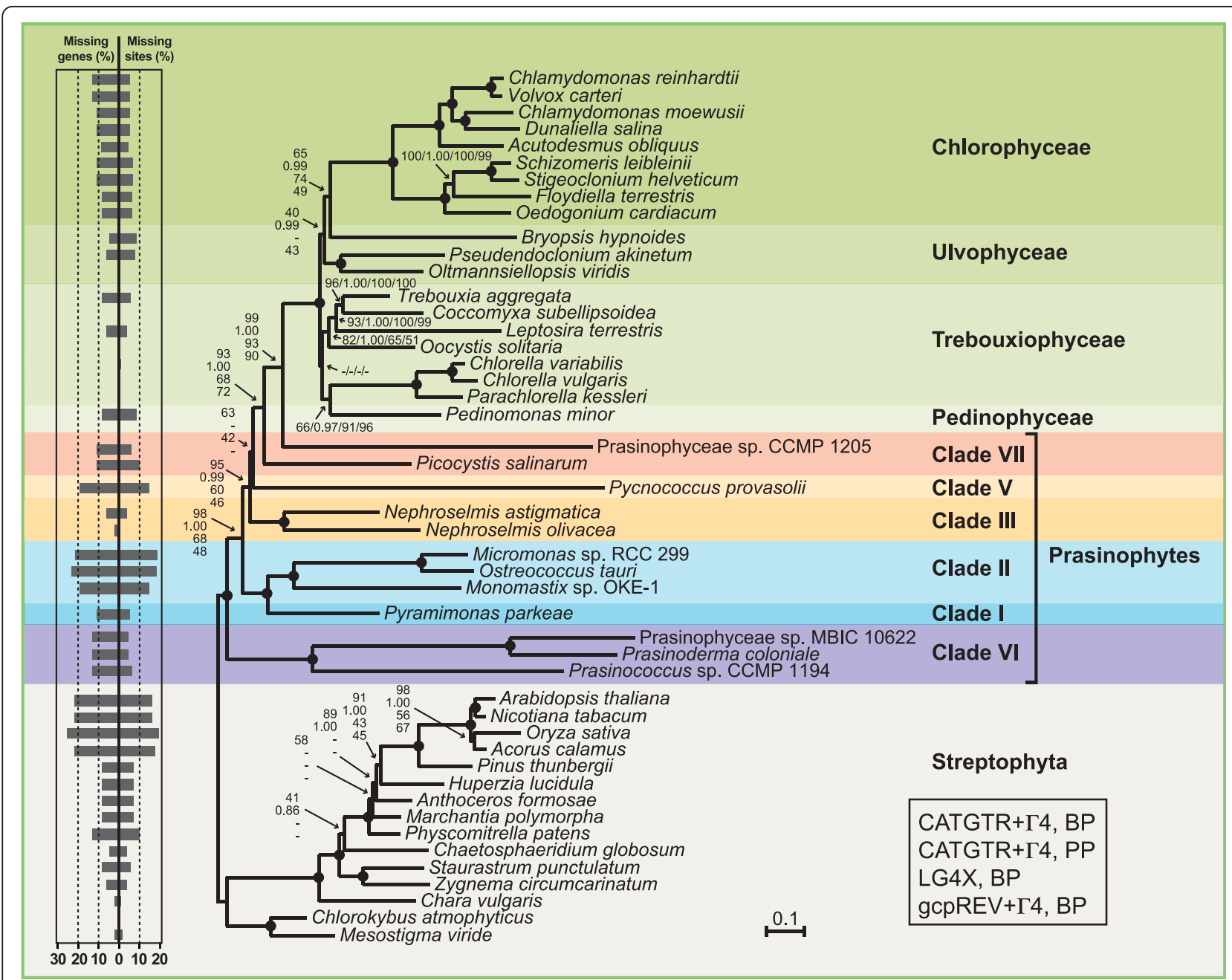

Figure 6 Relationships among prasinophyte lineages inferred using a data set of 14,382 positions assembled from 71 cpDNA-encoded proteins of $\mathbf{4 7}$ green plant taxa. Trees were inferred using PhyloBayes under the CATGTR $+\lceil 4$ model and RAxML under the LG4X and gcpREV $+\lceil 4$ models. In the ML analyses, the data set was partitioned by gene, with the model applied to each of the 71 partitions. The Bayesian majority-rule consensus tree is presented. Support values are reported on the nodes: from top to bottom, or from left to right, are shown the BP values for the CATGTR $+\lceil 4$ analyses, the PP values for the CATGTR $+\lceil 4$ analyses, and the BP values for the LG4X and gcpREV $+\lceil 4$ analyses. Dashes $(-)$ indicate lower than 0.95 PP or 40\% BP support values; black dots indicate that the corresponding nodes received 1.00 PP and 100\% BP support values. The histograms on the left indicate the proportion of missing genes and missing sites for each taxon. The scale bar denotes the estimated number of amino acid substitutions per site. 


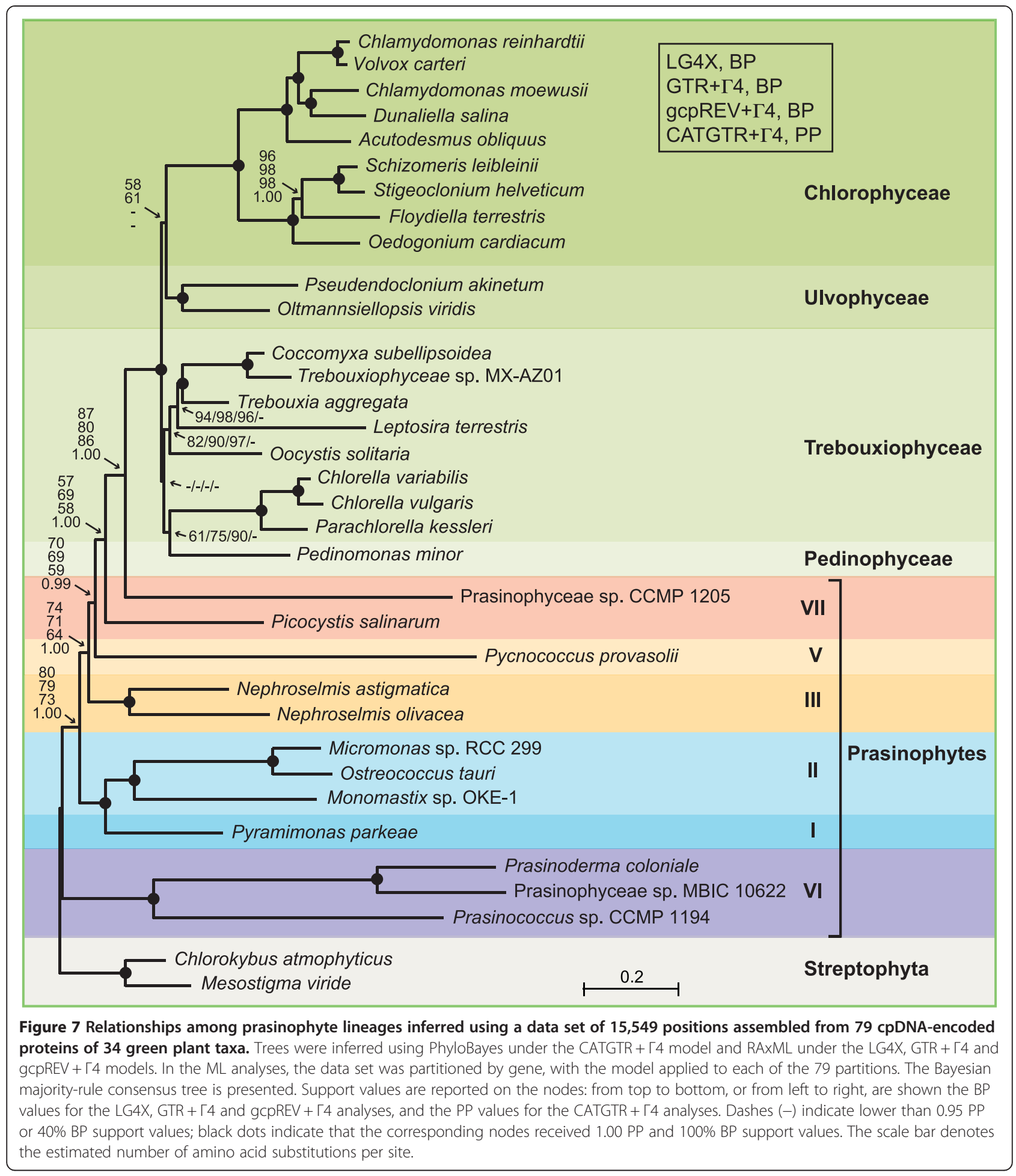

additional conserved genes relative to its Pyramimonas counterpart [25], which is more than three-fold smaller, two separate regions totaling about $27 \mathrm{~kb}$ lack any genes typically found in cpDNAs. Based on analyses of $\mathrm{A}+\mathrm{T}$ content and base composition of resident ORFs, it was suggested that these IR regions were acquired by lateral transfer [28]; this hypothesis was substantiated by the subsequent discovery that the orf389 encodes a putative protein with the conserved domain of phage associated DNA primases [25].

Recent $18 \mathrm{~S}$ rDNA phylogenies have uncovered multiple lineages in the Nephroselmidophyceae [29]. In the 
present study, sampling of Nephroselmis astigmatica, a representative of a lineage distinct from Nephroselmis olivacea, enabled us to gain insight into the stability of the quadripartite structure and ancestrally inherited gene clusters of cpDNA in the Nephroselmidophyceae. Compared to its Nephroselmis olivacea counterpart, the Nephroselmis astigmatica cpDNA has a much reduced size $(125,042 \mathrm{bp})$, which is mostly accounted for by a smaller IR (Table 1). At 13,742 bp, the IR of this species is comparable in size to that observed for Pyramimonas but is almost twice as large as that found for the mamiellaleans Ostreococcus and Micromonas. Although the IRs of the two Nephroselmis species differ in gene content in the region upstream of the rRNA operon, some of the genes downstream of this operon are conserved (trnR (acg), chlN, and chlL, see Figure 2). A notable difference concerns the location of $\operatorname{trn} L$ (caa): this gene lies at the immediate border of the large $\mathrm{SC}$ region in the Nephroselmis astigmatica IR (Figure 2); in contrast, it occurs near the small SC region in the Nephroselmis olivacea IR. Considering that $\operatorname{trnL}$ (caa) is usually included within the large SC region in other green plant cpDNAs having an ancestral quadripartite structure (e.g. Mesostigma [44] and Chlorokybus |[22]), the presence of this gene upstream of the rRNA operon in the Nephroselmis astigmatica IR can be simply explained by the expansion/contraction of the IR through gene conversion events [45]. With regards to the two SC regions, the gene content of each in both Nephroselmis cpDNAs fully conforms to the ancestral gene partitioning pattern. Given the conventional size of the Nephroselmis astigmatica IR, the presumably viral sequences in the Nephroselmis olivacea IR were likely captured specifically in the lineage containing the latter species. In this lineage, $\operatorname{trn} L$ (caa) switched position relative to the rRNA operon, probably by two successive inversions of internal IR sequences containing this operon. Positional changes of genes from one side of the rRNA operon to the other appear to have been frequent during chlorophyte evolution, as they have been observed for other chloroplast genomes displaying slight deviations from the ancestral quadripartite structure (e.g. the cpDNA of Pyramimonas [25], Pedinomonas [46], and the trebouxiophyte Parachlorella [46].

The Nephroselmis astigmatica chloroplast has a deficit of only five genes relative to that of Nephroselmis olivacea: seven genes are missing ( $a c c D, c e m A, f t s I, f t s W, t i l S$, rne, and $r n p B)$ and two extra ones are present $(y c f 20$ and $\operatorname{trn} V$ (gac)) (Figure 4). All of these nine genes display sporadic distributions in the other chlorophytes examined thus far. Interestingly, $\operatorname{trn} V$ (gac) is reported for the first time in chlorophyte cpDNAs; it is encoded not only in the Nephroselmis astigmatica cpDNA but also in the Picocystis (clade VII) genome.
The two Nephroselmis genomes share 18 blocks of colinear sequences that include a total of 88 genes (i.e. $72 \%$ of the Nephroselmis astigmatica and 69\% of the Nephroselmis olivacea genes) (Figure 2). The largest conserved clusters, which extend from rpl23 to petD and from trn $W$ (cca) to $y c f 12$, contain 16 and 15 genes, respectively. The Nephroselmis astigmatica genome contains several ancestral gene linkages that are missing in Nephroselmis olivacea and the Prasinococcales (e.g. 5' clpP-5' psbB, 3' psaI-3' psbJ, 3' rps2-5' atpI, 5' rbcL-5' atpB, $3^{\prime} \operatorname{trnH}$ (gug) $-5^{\prime} n d h C$, see Figure 5). Conversely, we find ancestral gene clusters in Nephroselmis olivacea that are missing from Nephroselmis astigmatica and prasinococcalean species (e.g., 3'trnS (uga)-5' ftsH, 5' rpl20-5' trnD (guc)); however, they are less abundant, indicating that ancestral gene linkages have undergone a higher degree of erosion in the Nephroselmis olivacea lineage.

While Nephroselmis olivacea is lacking any intron in its chloroplast, Nephroselmis astigmatica harbors two group I introns. These introns are found in the same genes as the five group I introns in Monomastix cpDNA (i.e. the large subunit (LSU) rRNA gene or $r r l$ and $p s b A$ ). The Nephroselmis astigmatica $r r l$ intron is inserted at site 1951 relative to the Escherichia coli 23S rRNA and like its Monomastix counterpart at the same site, it encodes a putative LAGLIDADG homing endonuclease gene (orf170). On the other hand, the Nephroselmis astigmatica $p s b A$ intron lacks an ORF and occupies an insertion site (site 750 in the corresponding Mesostigma psbA gene) that has not been previously reported for any green plant organelle intron.

\section{The cpDNAs of the two clade-VII representatives display contrasting patterns of evolution}

Because the picoalgae Picocystis and Prasinophyceae sp. CCMP 1205 are allied in 18S rDNA trees [12,15,29], their chloroplast genomes were expected to exhibit more similarity to each other than to their homologs in other prasinophyte clades. Even though they are both very densely packed with genes, they greatly diverge at the levels of their overall structure, gene content and gene order (Table 1). At 64,335 bp, the Prasinophyceae sp. CCMP 1205 cpDNA is the smallest chloroplast genome yet reported for a photosynthetic green plant. It lacks an IR and its 100 genes display a strong bias in distribution between the two DNA strands: two long segments containing 41 and 42 genes, all encoded on the same DNA strand, are separated from another by two smaller stretches of genes encoded on the opposite strand (Figure 3).

In contrast, the 81,133-bp Picocystis genome is more gene-rich (114 genes), contains a 10,364-bp IR, and does not exhibit any pronounced strand bias in gene distribution (Figure 3). As revealed by the gene contents of the $\mathrm{SC}$ regions, the quadripartite structure of this genome 
deviates considerably from both the ancestral gene partitioning pattern observed for the Nephroselmis cpDNAs and the derived quadripartite structure of the Ostreococcus and Micromonas genomes [26,27]. The gene repertoire of the Picocystis chloroplast, which displays 22 genes that are missing from its homolog in Prasinophyceae CCMP 1205, includes ten $n d h$ genes as well as three genes that have been identified thus far only in members of the Nephroselmidophyceae and/or Prasinococcales (i.e. ftsI, fts W, and $\operatorname{trn} V$ (gac)) (Figure 4).

The Picocystis and Prasinophyceae CCMP 1205 cpDNAs show a low level of synteny. Twelve blocks of colinear sequences containing 42 genes (i.e. $36 \%$ of the Picocystis and $41 \%$ of the Prasinophyceae genes) are conserved between these genomes (Figure 3); they consist uniquely of ancestral gene clusters that are present in most streptophyte and chlorophyte genomes. None of the two picoalgae exhibits an intact rRNA operon: even though the genes making up this operon are located in the Picocystis IR, the $r r l$ and $r r f$ (encoding 5S rRNA) genes have been rearranged, and like its Pyramimonas homolog, the $r r f$ gene of Prasinophyceae sp. CCMP 1205 appears to be missing (Figure 5). Of the two clade-VII cpDNAs, that of Picocystis clearly displays the highest degree of ancestral characters at the gene order level and in that regard, it also surpasses its prasinococcalean counterparts (Figure 5).

While no introns are found in the Prasinophyceae sp. CCMP 1205 cpDNA, a trans-spliced group II intron occurs in the Picocystis genome. The presence of this intron is somewhat puzzling, considering that, as observed for the Prasinophyceae sp. CCMP 1205 lineage, the chloroplast genome has been extensively streamlined in the lineage leading to Picocystis. The Picocystis intron is inserted within the $y c f 3$ gene at the same site (site 124 relative to Mesostigma $y c f 3$ ) as one of the cis-spliced $y c f 3$ introns found in charophytes and land plants $[47,48]$. It is split into two pieces that are $6.0 \mathrm{~kb}$ apart in the genome and occur as separate transcription units (Figure 3). The fragmentation site lies within domain IV of the potential intron secondary structure (Figure 8A), a common feature of trans-spliced group II introns [49]. Like most trans-spliced introns of this group, the Picocystis ycf3 intron lacks an ORF. Given that its domain I is degenerate and that the two pieces flanked by exon sequences must be assembled in trans at the RNA level through base-pairing interactions to yield a catalytically active intron structure, one or more nuclear-encoded factors are probably required to facilitate splicing. We have provided experimental evidence by RT-PCR analysis that the Picocystis intron is spliced properly and that the $y c f 3$ gene sequence is continuous at the RNA level (Figure 8b).

Among the Viridiplantae, chloroplast trans-spliced group II introns have been identified in streptophytes (in rps12), including charophytes $[47,48,50]$, and in representatives of all five major evolutionary lineages of the Chlorophyceae (in psaA, psaC, petD and/or rbcL) [19,46,51-53]. Trans-splicing of the tripartite group II intron in the $p s a A$ gene of the chlorophycean green alga Chlamydomonas reinhardtii (Chlamydomonadales) has been shown to be dependent upon at least 14 nuclear-encoded factors [54]. Our finding of a trans-spliced intron in a prasinophyte organelle is not unprecedented, as two trans-spliced group I introns have been uncovered in the mitochondria of Prasinoderma [55]. Both bipartite introns of this tiny prasinophyte occur within the LSU rRNA gene at positions where cis-spliced relatives containing homing endonucleases genes are found in organelles of other algae and as observed for other transspliced group I introns and even trans-spliced group II introns, the intron breakpoints correspond to the same region where the ORF occurs in cis-spliced orthologs. All trans-spliced organelle introns arose undoubtedly from cisspliced orthologs that were fractured by genome rearrangements [56]. It is possible that breakage of the cis-spliced ancestor of the Picocystis ycf3 intron (perhaps an intron gained from streptophytes by horizontal transfer) occurred when the chloroplast genome was less gene-dense and the intron carried a large loop in domain IV, because this would have offered better opportunities for recombination. Subsequently, the trans-configuration of the intron would have conferred increased resistance to intron loss by retroprocessing, owing to the lower probability that homologous recombination of a reverse transcribed mature $y c f 3$ mRNA with the distant exons generates an intronless version of the gene. Therefore, its trans-configuration probably explains why it survived in the streamlined chloroplast genome of Picocystis.

\section{Conclusions}

The phylogenies we inferred in this study enhance our understanding of the relationships among prasinophyte lineages. They are congruent with the branching order of prasinophyte lineages in nuclear-encoded SSU rDNA trees, even though the two clade-VII members analyzed, Picocystis and Prasinophyceae sp. CCMP 1205, form independent lineages instead of a clade, in the chloroplast trees (Figures 6 and 7). Only the position of the Pycnococcaceae relative to the other prasinophyte lineages examined could not be resolved with confidence.

In addition to providing support for the placement of the Prasinococcales in the deepest branch of the Chlorophyta, our comparative analysis of chloroplast genomes underscores the high variability in genome architecture among prasinophyte lineages, highlighting the strong pressure to maintain a small and compact chloroplast genome in picoplanktonic green algae. On the basis of the chloroplast phylogenomic trees we inferred, the IR was lost on at least four occasions during prasinophyte evolution (during the emergence of the Prasinococcales and in the lineages 


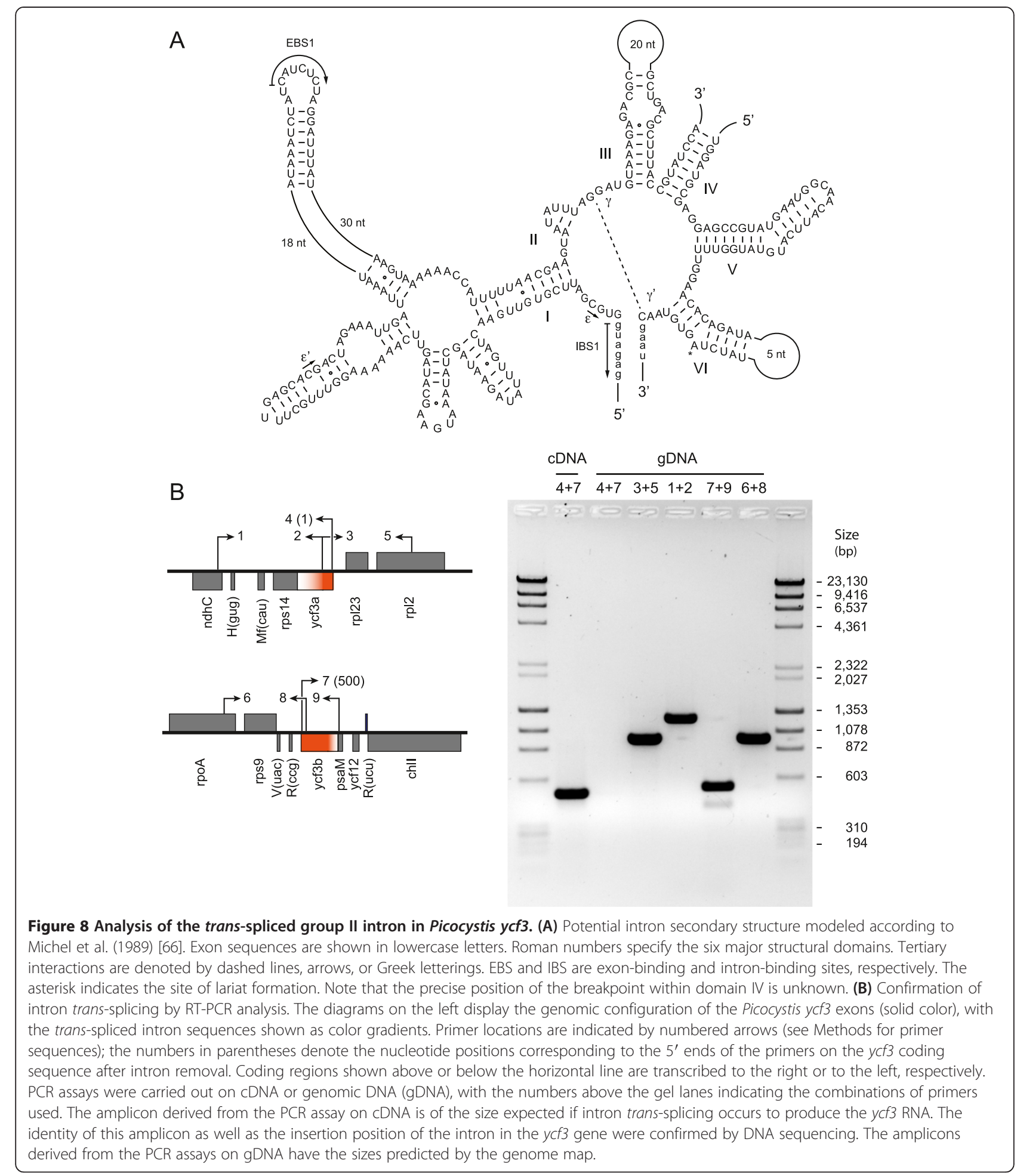

leading to Monomastix, Pycnococcus and Prasinophyceae sp. CCMP 1205 lineages). Considerable changes in the gene partitioning pattern of the ancestral quadripartite structure took place in two separate picoplanktonic lineages (Picocystis and the clade uniting Ostreococcus and Micromonas). In the Nephroselmidophyceae, the chloroplast genome retained a quadripartite structure of the ancestral type but the IR changed considerably in size and gene content through gain of horizontally transferred sequences (in the lineage leading to Nephroselmis olivacea), shifts of IR boundaries, and relocalization of trnL (caa) relative to the rRNA operon. Although many genes 
sustained independent losses in multiple prasinophyte lineages, the Prasinococcales have retained a set of six genes that are missing in all other chlorophytes examined so far. The widely divergent traits uncovered for the genomes of the picoalgae Picocystis and Prasinophyceae sp. CCMP 1205 are consistent with the placement of these two clade-VII members in separate lineages. The 64,335-bp IR-less cpDNA of the latter alga is the smallest chloroplast genome yet reported for a photosynthetic green plant. The ycf3 intron of the tiny Picocystis is, to our knowledge, the first chloroplast trans-spliced intron documented for prasinophytes; it is also the only intron known in the chloroplast of a picoplanktonic chlorophyte.

\section{Methods}

\section{Strains and culture conditions}

Strains of Prasinococcus sp. (CCMP 1194), Prasinoderma coloniale (CCMP 1220), Picocystis salinarum (CCMP 1897) and Prasinophyceae sp. (CCMP 1205) were obtained from the Provasoli-Guillard National Center for Marine Algae and Microbiota [8]. Nephroselmis astigmatica (NIES 252) originates from the Microbial Culture Collection at the National Institute of Environmental Studies [9] and Prasinophyceae sp. (NBRC 102842, formally MBIC 106222) from the NITE (National Institute of Technology and Evaluation) Biological Resource Center [57]. All strains were grown in $\mathrm{K}$ medium [58] at $18^{\circ} \mathrm{C}$ under alternating $12 \mathrm{~h}$-light/12 h-dark periods.

\section{Genome sequencing, assembly and annotation}

Total cellular DNA was extracted and run on $\mathrm{CsCl}$ bisbenzimide (1.67 g/ml CsCl, $200 \mu \mathrm{g} / \mathrm{ml}$ bisbenzimide) isopycnic gradients as described [59]. The resulting gradient was fractionated into 40 fractions $(120 \mu \mathrm{l}$ each) using a Density Gradient Fractionation System (Brandel, Gaithersburg, MD, USA). After precipitation with ethanol, DNA from each of the 20 lowest density fractions was digested with EcoRI and the fractions displaying digestion patterns of low complexity DNA on agarose gels were selected for sequencing. However, as the isolation of A + T-rich organellar DNA proved unsuccessful for Nephroselmis astigmatica, total cellular DNA of this alga was used for sequencing.

Sequencing of the Prasinophyceae sp. CCMP 1205 cpDNA was carried out using random clones and Sanger chemistry. Random clone libraries were prepared from 1500-2000-bp fragments derived from the A + T rich DNA fractions using the pSMART-HCKan (Lucigen Corporation, Middleton, WI) plasmid. Positive clones were selected by hybridization of each plasmid library with the original DNA used for cloning. DNA templates were amplified using the Illustra TempliPhi Amplification Kit (GE Healthcare, Baie d'Urfé, Canada) and sequenced with the PRISM BigDye terminator cycle sequencing ready reaction kit (Applied
Biosystems, Foster City, CA) on Applied Biosystems model 3130XL DNA sequencers, using T3 and T7 primers as well as oligonucleotides complementary to internal regions of the plasmid DNA inserts. The resulting sequences were edited and assembled using SEQUENCHER 5.1 (Gene Codes Corporation, Ann Arbor, MI). Genomic regions not represented in the sequence assemblies or plasmid clones were directly sequenced from polymerase chain reaction (PCR)-amplified fragments using internal primers. Note that the 11 Prasinophyceae CCMP 1205 chloroplast genes that Matsumoto et al. [60] have previously examined share identical or nearly identical sequences with their counterparts in the genome we assembled, thus confirming that this chloroplast genome is that of the genuine CCMP 1205 strain.

For all the other algal cpDNAs, a shotgun library of A + T-rich organellar DNA or total cellular DNA (700 bp fragments) was constructed using the GS-FLX Titanium Rapid Library Preparation Kit from Roche 454 Life Sciences (Branford, CT, USA). Library construction as well as 454 GS-FLX DNA Titanium pyrosequencing were carried out by the Plateforme d'Analyses Génomiques de l'Université Laval [10]. Reads were assembled with gsAssembler 2.5 from the Roche GS Data Analysis Software package, and contigs were visualized, linked, edited and polished using the CONSED 22 package [61]. Contigs of chloroplast origin were identified by BLAST searches against a local database of organelle genomes. Regions spanning gaps in the cpDNA assemblies were amplified by PCR with primers specific to the flanking sequences. Purified PCR products were sequenced using Sanger chemistry with the PRISM BigDye terminator cycle sequencing ready reaction kit (Applied Biosystems, Foster City, CA, USA) by the Plateforme d'Analyses Génomiques. Average genome coverage ranged from 80-290 in the assemblies of all cpDNAs, except that of Nephroselmis astigmatica. As an average coverage of less than 10 was obtained for the latter cpDNA, we confirmed the 454 sequence assembly with 6.5 millions paired-end reads of $300 \mathrm{bp}$ generated on the MiSeq sequencing platform (Illumina, San Diego, CA, USA). Following de novo assembly of these reads using Ray 2.3.1 [62] and a kmer size of 61, we obtained two overlapping chloroplast contigs, each containing a SC region (small or large SC) flanked at both ends with part of the IR sequence. After identification of the IR-SC junction in each contig, we were able to assemble the two contigs into a circular molecule that has essentially the same sequence as that obtained with the 454 data.

Genes and ORFs were identified on the final assemblies using a custom-built suite of bioinformatics tools as described previously [63]. Genes coding for rRNAs and tRNAs were localized using RNAmmer [64] and tRNAscan-SE [65], respectively. Intron boundaries were 
determined by modeling intron secondary structures $[66,67]$ and by comparing intron-containing genes with intronless homologs. Gene maps were drawn using OGDRAW [68].

To estimate the proportion of repeated sequences in each of the sequenced chloroplast genomes, repeats $\geq 30$ bp were retrieved using REPFIND of the REPuter 2.74 program [69] with the options $-\mathrm{f}$ (forward) - $\mathrm{p}$ (palindromic) $-\mathrm{l}$ (minimum length $=30 \mathrm{bp}$ ) -allmax and then were masked on the genome sequence using REPEATMASKER [70] running under the Crossmatch search engine [71].

\section{RNA extraction and RT-PCR reactions}

Total RNA from Picocystis was extracted from cells ground in liquid nitrogen with the E.Z.N.A Total RNA Kit of Omega bio-tek (Norcross, GA, USA). To confirm that the $y c f 3$ transcript undergoes trans-splicing and also to verify the insertion position of the trans-spliced intron, RT-PCR reactions were performed on the RNA preparation using the Qiagen One-Step RT-PCR kit with the primers ATGCCTAGATCACAACGAAATG $(40,810$, primer 4) and GTTCGACCTGTTACTTTCAACC $(46,919$, primer 7). The RT-PCR product was sequenced using Sanger chemistry as described above. The genomic positions of the $y c f 3 a$ and $y c f 3 b$ exons were also confirmed by carrying out PCR reactions on genomic DNA using various combinations of the following primers: CTCAT ACGTTGTTCGTTGAATG $(39,456$, primer 1$)$, GAAGC ATTCAGTTATTACCGAG (40,711, primer 2), CTCGGT AATAACTGAATGCTTC $(40,690$, primer 3$)$, TATGTA CTTCAGTACCTAGAGG $(41,704$, primer 5), GCCTATC CGACAAGTCAATTAC $(46,061$, primer 6$)$, GCAATAG AAAACGATCAGACAG (47,052, primer 8), and TT GCATTACGTTTAGGTACTGC (47,452, primer 9). For each primer, the coordinate of the genome sequence corresponding to the $5^{\prime}$ end is indicated in parentheses together with the primer numbering shown in Figure 8B.

\section{Analyses of gene order data}

We used a custom-built program to identify all pairs of signed genes (i.e., taking into account gene polarity) that are conserved in at least two of the 14 compared cpDNAs (those of the 12 prasinophytes and of the streptophyte algae Mesostigma and Chlorokybus). This program was also employed to detect the regions that display the same gene order in selected pairs of prasinophyte cpDNAs.

\section{Phylogenomic analyses}

The chloroplast genomes of 47 green algae were used for phylogenomic analysis. The GenBank accession numbers of these green algal genomes are as follows: Mesostigma viride, [GenBank:NC_002186]; Chlorokybus atmophyticus, [GenBank:NC_008822]; Chara vulgaris, [GenBank:NC_008097]; Chaetosphaeridium globosum,
[GenBank:NC_004115]; Zygnema circumcarinatum, [GenBank:NC_008117]; Staurastrum punctulatum, [GenBank: NC_008116]; Physcomitrella patens, [GenBank:NC_005087]; Marchantia polymorpha, [GenBank:NC_001319]; Anthoceros formosae, [GenBank:NC_004543]; Huperzia lucidula, [GenBank:NC_006861]; Pinus thunbergii, [GenBank: NC_001631]; Acorus calamus, [GenBank:NC_007407]; Oryza sativa, [GenBank:NC_001320]; Nicotiana tabacum, [GenBank:NC_001879]; Arabidopsis thaliana, [GenBank:NC_000932]; Prasinococcus sp. CCMP 1194, [GenBank:KJ746597]; Prasinoderma coloniale CCMP 1220, [GenBank:KJ746598]; Prasinophyceae sp. MBIC 106222, [GenBank:KJ746602]; Pyramimonas parkeae, [GenBank:NC_012099]; Monomastix sp. OKE-1, [GenBank:NC_012101]; Ostreococcus tauri, [GenBank: NC_008289]; Micromonas sp. RCC 299, [GenBank:NC_ 012575]; Nephroselmis olivacea, [GenBank:NC_000927]; Nephroselmis astigmatica, [GenBank:KJ746600]; Pycnococcus provasolii, [GenBank:NC_012097]; Picocystis salinarum, [GenBank:KJ746599]; Prasinophyceae sp. CCMP 1205, [GenBank:KJ746601]; Pedinomonas minor, [GenBank:NC_016733]; Chlorella vulgaris, [GenBank:NC_ 001865]; Chlorella variabilis, [GenBank:NC_015359]; Oocystis solitaria, [GenBank:FJ968739]; Parachlorella kessleri, [GenBank:NC_012978]; Coccomyxa subellipsoidea, [GenBank:NC_015084]; Leptosira terrestris, [GenBank: NC_009681]; Trebouxia aggregata, [GenBank:EU123962EU124002]; Bryopsis hypnoides, [GenBank:NC_013359]; Oltmannsiellopsis viridis, [GenBank:NC_008099]; Pseudendoclonium akinetum, [GenBank:NC_008114]; Oedogonium cardiacum, [GenBank:NC_011031]; Floydiella terrestris, [GenBank:NC_014346]; Stigeoclonium helveticum, [GenBank:NC_008372]; Schizomeris leibleinii, [GenBank:NC_ 015645]; Acutodesmus obliquus, [GenBank:NC_008101]; Chlamydomonas moewusii, [GenBank:EF587443-EF58 7503]; Dunaliella salina, [GenBank:NC_016732]; Volvox carteri f. nagariensis, [GenBank:GU084820]; and Chlamydomonas reinhardtii, [GenBank:NC_005353].

We selected the protein-coding genes that are shared by at least 25 of the 47 taxa. Seventy-one genes met this criterion: accD, atpA, B, E, F, $H, I, \operatorname{ccs} A, \operatorname{cem} A, \operatorname{chl} B, I, L, N$, $P$, ftsH, infA, petA, $B, D, G, L, p s a A, B, C, I, J, M, p s b A, B$, $C, D, E, F, H, I, J, K, L, M, N, T, Z, r b c L, r p l 2,5,14,16,20$, 23, 32, 36, rроA, B, C1, C2, rps2, 3, 4, 7, 8, 9, 11, 12, 14, 18, 19, tufA, ycf1, 3, 4, 12. An amino acid data set of 14,382 positions was prepared as follows: the deduced amino acid sequences from the 71 individual genes were aligned using MUSCLE 3.7 [72], the ambiguously aligned regions in each alignment were removed using TRIMAL 1.3 [73] with the options block $=7$, gt $=0.7$, st $=0.001$ and $\mathrm{sw}=3$, and the protein alignments were concatenated. Missing characters represent $7.4 \%$ of the data set.

The amino acid data set of 14,382 positions was analyzed using both the ML and Bayesian inference methods. 
The Bayesian phylogeny was inferred using PhyloBayes 3.3f [74] and the site-heterogeneous CATGTR $+\Gamma 4$ model [34]. To identify the best tree, five independent chains were run for 6,300 cycles under this model and a consensus topology was calculated from the saved trees using the BPCOMP program of PhyloBayes after a burn-in of 1,500 cycles. Under these conditions, the largest discrepancy observed across all bipartitions in the consensus topology (maxdiff) was 0.26 , indicating that convergence between the five chains was achieved. To determine the confidence level at each node of the best tree, 100 pseudoreplicates were generated using the SEQBOOT program of the PHYLIP package [75], chains were run using 2,000 cycles (with each cycle sampled) for each pseudoreplicate, and a consensus tree was computed with the READPB program of PhyloBayes after elimination of 500 burn-in trees. A bootstrap consensus tree, whose topology was identical to the best tree, was generated from the 100 resulting consensus trees using the CONSENSE program of the PHYLIP package. The ML analyses were carried out using RAxML 8.0.20 [76] and the LG4X [39] and gcpREV $+\Gamma 4$ [40] models of sequence evolution. In these analyses, the data set was partitioned by gene, with the model applied to each partition. Confidence of branch points was estimated by fast-bootstrap analysis $(\mathrm{f}=\mathrm{a})$ with 100 replicates.

ML and Bayesian phylogenies were also inferred from an amino acid data set of 15,549 positions that was assembled from 79 cpDNA-encoded proteins of 32 chlorophytes and two streptophytes. Relative to the amino acid data set of 14,382 positions, this data set includes the deduced protein sequences of eight extra genes (cys $A$, cysT, minD, rpl12, rpl19, tils, ycf20 and $y c f 47)$ and the sequences of an additional trebouxiophyte (Trebouxiophyceae sp. MX-AZ01, [GenBank:NC_018569]). It was prepared as described above, except that the TRIMAL filtration was carried out with the options block $=6$, gt $=$ 0.7 , st $=0.005$ and $\mathrm{sw}=3$. Missing characters represent 9.2\% of the data set. The RAxML and PhyloBayes analyses were carried out as described for the data set of 14,382 positions.

\section{Availability of supporting data}

The chloroplast genome sequences generated in this study are available in the GenBank database under the accession numbers KJ746597-KJ746602. The data sets supporting the results of this article are available in the TreeBASE repository (Study ID 16332) [77].

\section{Abbreviations}

BP: Bootstrap proportion; cpDNA: Chloroplast DNA; IR: Inverted repeat; LSU: Large subunit; PP: Posterior probability; SC: Single copy; SSU: Small subunit.

\section{Competing interests}

The authors declare that they have no competing interests.

\section{Authors' contributions}

$\mathrm{CL}$ and MT conceived the study and wrote the manuscript. CO performed all the experimental work and determined the secondary structure model of the Picocystis ycf3 intron. CO and CL carried out the assembly of the chloroplast genomes. $\mathrm{CL}$ performed most of the sequence analyses, and generated the figures. MT also contributed to the analysis and interpretation of the data. All authors read and approved the final manuscript.

\section{Acknowledgements}

This work was supported by a Discovery grant from the Natural Sciences and Engineering Research Council of Canada (to C.L. and M.T.).

Received: 28 April 2014 Accepted: 25 September 2014 Published: 4 October 2014

\section{References}

1. Leliaert F, Smith DR, Moreau $H$, Herron MD, Verbruggen $H$, Delwiche CF, De Clerck O: Phylogeny and molecular evolution of the green algae. CRC Crit Rev Plant Sci 2012, 31:1-46.

2. Leliaert F, Verbruggen $H$, Zechman FW: Into the deep: new discoveries at the base of the green plant phylogeny. Bioessays 2011, 33(9):683-692.

3. Lewis LA, McCourt RM: Green algae and the origin of land plants. Am J Bot 2004, 91(10):1535-1556.

4. Mattox KR, Stewart KD: Classification of the green algae: a concept based on comparative cytology. In The Systematics of the Green Algae. Edited by Irvine DEG, John DM. London: Academic Press; 1984:29-72.

5. Latasa M, Scharek R, Le Gall F, Guillou L: Pigment suites and taxonomic groups in Prasinophyceae. J Phycol 2004, 40(6):1149-1155.

6. Melkonian M: Phylum Chlorophyta. Class Prasinophyceae. In Handbook of Protoctista the Structure, Cultivation, Habitats and Life Histories of the Eukaryotic Microorganisms and their Descendants Exclusive of Animals, Plants and Fungi. Edited by Margulis L, Corliss JO, Melkonian M, Chapman DJ. Boston: Jones and Bartlett Publishers; 1990:600-607.

7. O'Kelly CJ: Flagellar apparatus architecture and the phylogeny of "green algae": chlorophytes, euglenoids, glaucophytes. In The Cytoskeleton of the Algae. Edited by Menzel D. Boca Raton: CRC Press; 1992:315-345.

8. Sym SD, Pienaar RN: The class Prasinophyceae. In Progress Phycol Res, Volume 9. Edited by Round FE, Chapman DJ. Bristol: Biopress Ltd; 1993:281-376.

9. Chrétiennot-Dinet MJ, Courties C, Vaquer A, Neveux J, Claustre H, Lautier J, Machado MC: A new marine picoeucaryote: Ostreococcus tauri gen. et sp. nov. (Chlorophyta, Prasinophyceae). Phycologia 1995, 34(4):285-292.

10. Courties C, Vaquer A, Troussellier M, Lautier J, Chretiennot-Dinet MJ, Neveux J, Machado C, Claustre H: Smallest eukaryotic organism. Nature 1994, 370(6487):255-255.

11. Fawley MW, Yun Y, Qin M: Phylogenetic analyses of $18 \mathrm{~S}$ rDNA sequences reveal a new coccoid lineage of the Prasinophyceae (Chlorophyta). J Phycol 2000, 36(2):387-393.

12. Guillou L, Eikrem W, Chrétiennot-Dinet M-J, Le Gall F, Massana R, Romari K, Pedrós-Alió C, Vaulot D: Diversity of picoplanktonic prasinophytes assessed by direct nuclear SSU rDNA sequencing of environmental samples and novel isolates retrieved from oceanic and coastal marine ecosystems. Protist 2004, 155:193-214.

13. Nakayama T, Marin B, Kranz HD, Surek B, Huss VAR, Inouye I, Melkonian M: The basal position of scaly green flagellates among the green algae (Chlorophyta) is revealed by analyses of nuclear-encoded SSU rRNA sequences. Protist 1998, 149:367-380.

14. Viprey M, Guillou L, Ferreol M, Vaulot D: Wide genetic diversity of picoplanktonic green algae (Chloroplastida) in the Mediterranean Sea uncovered by a phylum-biased PCR approach. Environ Microbiol 2008, 10(7):1804-1822.

15. Marin B, Melkonian M: Molecular phylogeny and classification of the Mamiellophyceae class. nov. (Chlorophyta) based on sequence comparisons of the nuclear- and plastid-encoded rRNA operons. Protist 2010, 161(2):304-336.

16. Cavalier-Smith T: The origin, losses and gains of Chloroplasts. In Origins of Plastids. Edited by Lewin RA. US: Springer; 1993:291-348.

17. Massjuk N: Chlorodendrophyceae class. nov. (Chlorophyta, Viridiplantae) in the Ukrainian flora: I. The volume, phylogenetic relations and taxonomical status. Ukr Bot J 2006, 63:601-614.

18. Raven J: Picophytoplankton. Progress Phycol Res 1999, 13:33-106. 
19. Brouard JS, Otis C, Lemieux C, Turmel M: The exceptionally large chloroplast genome of the green alga Floydiella terrestris illuminates the evolutionary history of the Chlorophyceae. Genome Biol Evol 2010, 2:240-256.

20. Grewe F, Guo W, Gubbels EA, Hansen AK, Mower JP: Complete plastid genomes from Ophioglossum californicum, Psilotum nudum, and Equisetum hyemale reveal an ancestral land plant genome structure and resolve the position of Equisetales among monilophytes. BMC Evol Biol 2013, 13:8.

21. Jansen RK, Cai Z, Raubeson LA, Daniell H, Depamphilis CW, Leebens-Mack J, Muller KF, Guisinger-Bellian M, Haberle RC, Hansen AK, Chumley TW, Lee SB, Peery R, McNeal JR, Kuehl JV, Boore JL: Analysis of 81 genes from 64 plastid genomes resolves relationships in angiosperms and identifies genome-scale evolutionary patterns. Proc Natl Acad Sci U S A 2007 104(49):19369-19374.

22. Lemieux C, Otis C, Turmel M: A clade uniting the green algae Mesostigma viride and Chlorokybus atmophyticus represents the deepest branch of the Streptophyta in chloroplast genome-based phylogenies. BMC Biol 2007, 5:2.

23. Qiu YL, Li LB, Wang B, Chen ZD, Knoop V, Groth-Malonek M, Dombrovska O, Lee J, Kent L, Rest J, Estabrook GF, Hendry TA, Taylor DW, Testa CM, Ambros M, Crandall-Stotler B, Duff RJ, Stech M, Frey W, Quandt D, Davis CC: The deepest divergences in land plants inferred from phylogenomic evidence. Proc Natl Acad Sci U S A 2006, 103(42):15511-15516.

24. Turmel M, Brouard JS, Gagnon C, Otis C, Lemieux C: Deep division in the Chlorophyceae (Chlorophyta) revealed by chloroplast phylogenomic analyses. J Phycol 2008, 44(3):739-750.

25. Turmel M, Gagnon MC, O'Kelly CJ, Otis C, Lemieux C: The chloroplast genomes of the green algae Pyramimonas, Monomastix, and Pycnococcus shed new light on the evolutionary history of prasinophytes and the origin of the secondary chloroplasts of euglenids. Mol Biol Evol 2009, 26(3):631-648.

26. Worden $A Z$, J-h L, Mock T, Rouzé $P$, Simmons MP, Aerts AL, Allen AE Cuvelier ML, Derelle E, Everett MV, Foulon E, Grimwood J, Gundlach H, Henrissat B, Napoli C, Badger JH, Coutinho PM, Demir E, Dubchak I, Gentemann C, Eikrem W, Gready JE, John U, Lanier W, Lindquist EA, Panaud O, Pangilinan J, Paulsen I, Piegu B, Poliakov A: Green evolution and dynamic adaptations revealed by genomes of the marine picoeukaryotes Micromonas. Science 2009, 324:268-272.

27. Robbens S, Derelle E, Ferraz C, Wuyts J, Moreau H, Van de Peer Y: The complete chloroplast and mitochondrial DNA sequence of Ostreococcus tauri: organelle genomes of the smallest eukaryote are examples of compaction. Mol Biol Evol 2007, 24:956-968

28. Turmel M, Otis C, Lemieux C: The complete chloroplast DNA sequence of the green alga Nephroselmis olivacea: insights into the architecture of ancestral chloroplast genomes. Proc Natl Acad Sci U S A 1999, 96:10248-10253.

29. Nakayama T, Suda S, Kawachi M, Inouye I: Phylogeny and ultrastructure of Nephroselmis and Pseudoscourfieldia (Chlorophyta), including the description of Nephroselmis anterostigmatica sp. nov. and a proposal for the Nephroselmidales ord. nov. Phycologia 2007, 46(6):680-697.

30. Cox CJ, Li B, Foster PG, Embley TM, Civan P: Conflicting phylogenies for early land plants are caused by composition biases among synonymous substitutions. Syst Biol 2014, 63(2):272-279.

31. Li B, Lopes JS, Foster PG, Embley TM, Cox CJ: Compositional biases among synonymous substitutions cause conflict between gene and protein trees for plastid origins. Mol Biol Evol 2014, 31(7):1697-1709.

32. Rota-Stabelli O, Lartillot N, Philippe H, Pisani D: Serine codon-usage bias in deep phylogenomics: pancrustacean relationships as a case study. Syst Biol 2013, 62(1):121-133.

33. Lartillot N, Brinkmann $H$, Philippe $H$ : Suppression of long-branch attraction artefacts in the animal phylogeny using a site-heterogeneous model. BMC Evol Biol 2007, 7(Suppl 1):S4.

34. Lartillot N, Philippe $H$ : A Bayesian mixture model for across-site heterogeneities in the amino-acid replacement process. Mol Biol Evol 2004, 21(6):1095-1109.

35. Philippe H, Brinkmann H, Copley RR, Moroz LL, Nakano H, Poustka AJ, Wallberg A, Peterson KJ, Telford MJ: Acoelomorph flatworms are deuterostomes related to Xenoturbella. Nature 2011, 470(7333):255-260.

36. Philippe H, Brinkmann H, Lavrov DV, Littlewood DTJ, Manuel M, Worheide $G$, Baurain D: Resolving difficult phylogenetic questions: why more sequences are not enough. PLos Biol 2011, 9(3):e1000602.
37. Smith DR, Burki F, Yamada T, Grimwood J, Grigoriev IV, Van Etten JL, Keeling PJ: The GC-rich mitochondrial and plastid genomes of the green alga Coccomyxa give insight into the evolution of organelle DNA nucleotide landscape. PLoS One 2011, 6(8):e23624.

38. Marin B: Nested in the Chlorellales or independent class? Phylogeny and classification of the Pedinophyceae (Viridiplantae) revealed by molecular phylogenetic analyses of complete nuclear and plastid-encoded rRNA operons. Protist 2012, 163(5):778-805.

39. Le SQ, Dang CC, Gascuel O: Modeling protein evolution with several amino acid replacement matrices depending on site rates. Mol Biol Evol 2012, 29(10):2921-2936.

40. Cox CJ, Foster PG: A 20-state empirical amino-acid substitution model for green plant chloroplasts. Mol Phylogenet Evol 2013, 68(2):218-220.

41. Felsenstein J: Cases in which parsimony or compatibility methods will be positively misleading. Syst Zool 1978, 27(4):401-410.

42. Kumar AM, Schaub U, Söll D, Ujwal ML: Glutamyl-transfer RNA: at the crossroad between chlorophyll and protein biosynthesis. Trends Plant Sci 1996, 1(11):371-376.

43. de Cambiaire JC, Otis C, Lemieux C, Turmel M: The complete chloroplast genome sequence of the chlorophycean green alga Scenedesmus obliquus reveals a compact gene organization and a biased distribution of genes on the two DNA strands. BMC Evol Biol 2006, 6:37.

44. Lemieux C, Otis C, Turmel M: Ancestral chloroplast genome in Mesostigma viride reveals an early branch of green plant evolution. Nature 2000, 403(6770):649-652.

45. Goulding SE, Olmstead RG, Morden CW, Wolfe KH: Ebb and flow of the chloroplast inverted repeat. Mol Gen Genet 1996, 252(1-2):195-206.

46. Turmel M, Otis C, Lemieux C: The chloroplast genomes of the green algae Pedinomonas minor, Parachlorella kessleri, and Oocystis solitaria reveal a shared ancestry between the Pedinomonadales and Chlorellales. Mol Biol Evol 2009, 26(10):2317-2331.

47. Turmel M, Otis C, Lemieux C: The complete chloroplast DNA sequences of the charophycean green algae Staurastrum and Zygnema reveal that the chloroplast genome underwent extensive changes during the evolution of the Zygnematales. BMC Biol 2005, 3:22

48. Turmel $M$, Otis $C$, Lemieux $C$ : The chloroplast genome sequence of Chara vulgaris sheds new light into the closest green algal relatives of land plants. Mol Biol Evol 2006, 23(6):1324-1338.

49. Michel F, Ferat J: Structure and activities of group II introns. Annu Rev Biochem 1995, 64(1):435-461.

50. Turmel M, Otis C, Lemieux C: The chloroplast and mitochondrial genome sequences of the charophyte Chaetosphaeridium globosum: insights into the timing of the events that restructured organelle DNAs within the green algal lineage that led to land plants. Proc Natl Acad Sci U S A 2002, 99(17):11275-11280.

51. Bélanger AS, Brouard JS, Charlebois P, Otis C, Lemieux C, Turmel M: Distinctive architecture of the chloroplast genome in the chlorophycean green alga Stigeoclonium helveticum. Mol Genet Genomics 2006, 276(5):464-477.

52. Brouard JS, Otis C, Lemieux C, Turmel M: Chloroplast DNA sequence of the green alga Oedogonium cardiacum (Chlorophyceae): unique genome architecture, derived characters shared with the Chaetophorales and novel genes acquired through horizontal transfer. BMC Genomics 2008, 9:290.

53. Kück U, Choquet $Y$, Schneider M, Dron M, Bennoun P: Structural and transcription analysis of two homologous genes for the P700 chlorophyll $a$-apoproteins in Chlamydomonas reinhardii: evidence for in vivo trans-splicing. EMBO J 1987, 6:2185-2195.

54. Glanz S, Kück U: Trans-splicing of organelle introns - a detour to continuous RNAs. Bioessays 2009, 31(9):921-934.

55. Pombert JF, Otis C, Turmel M, Lemieux C: The mitochondrial genome of the prasinophyte Prasinoderma coloniale reveals two trans-spliced group I introns in the large subunit rRNA gene. PLoS One 2013, 8(12):e84325.

56. Bonen L: Evolution of mitochondrial introns in plants and photosynthetic microbes. Adv Bot Res 2012, 63:155-186.

57. Biological Resource Center of the National Institute of Technology and Evaluation. In http://www.nbrc.nite.go.jp/e/.

58. Keller MD, Seluin RC, Claus W, Guillard RRL: Media for the culture of oceanic ultraphytoplankton. J Phycol 1987, 23:633-638.

59. Turmel M, Lemieux C, Burger G, Lang BF, Otis C, Plante I, Gray MW: The complete mitochondrial DNA sequences of Nephroselmis olivacea and Pedinomonas minor. Two radically different evolutionary patterns within green algae. Plant Cell 1999, 11:1717-1730. 
60. Matsumoto T, Shinozaki F, Chikuni T, Yabuki A, Takishita K, Kawachi M, Nakayama T, Inouye I, Hashimoto T, Inagaki Y: Green-colored plastids in the dinoflagellate genus Lepidodinium are of core chlorophyte origin. Protist 2011, 162(2):268-276.

61. Gordon D, Abajian C, Green P: Consed: a graphical tool for sequence finishing. Genome Res 1998, 8:195-202.

62. Boisvert S, Laviolette F, Corbeil J: Ray: simultaneous assembly of reads from a mix of high-throughput sequencing technologies. J Comput Biol 2010, 17(11):1519-1533.

63. Pombert JF, Otis C, Lemieux C, Turmel M: The chloroplast genome sequence of the green alga Pseudendoclonium akinetum (Ulvophyceae) reveals unusual structural features and new insights into the branching order of chlorophyte lineages. Mol Biol Evol 2005, 22(9):1903-1918.

64. Lagesen K, Hallin P, Rodland EA, Staerfeldt HH, Rognes T, Ussery DW: RNAmmer: consistent and rapid annotation of ribosomal RNA genes. Nucleic Acids Res 2007, 35(9):3100-3108.

65. Lowe TM, Eddy SR: tRNAscan-SE: a program for improved detection of transfer RNA genes in genomic sequence. Nucleic Acids Res 1997, 25(5):955-964.

66. Michel F, Umesono $\mathrm{K}$, Ozeki $\mathrm{H}$ : Comparative and functional anatomy of group II catalytic introns - a review. Gene 1989, 82(1):5-30.

67. Michel F, Westhof E: Modelling of the three-dimensional architecture of group I catalytic introns based on comparative sequence analysis. J Mol Biol 1990, 216:585-610.

68. Lohse M, Drechsel O, Bock R: OrganellarGenomeDRAW (OGDRAW): a too for the easy generation of high-quality custom graphical maps of plastid and mitochondrial genomes. Curr Genet 2007, 52:267-274.

69. Kurtz S, Choudhuri JV, Ohlebusch E, Schleiermacher C, Stoye J, Giegerich R: REPuter: the manifold applications of repeat analysis on a genomic scale. Nucleic Acids Res 2001, 29:4633-4642.

70. Repeat Masker. In http://www.repeatmasker.org/.

71. Cross match. In http://www.phrap.org/phredphrapconsed.html.

72. Edgar RC: MUSCLE: multiple sequence alignment with high accuracy and high throughput. Nucleic Acids Res 2004, 32(5):1792-1797.

73. Capella-Gutierrez S, Silla-Martinez JM, Gabaldon T: trimAl: a tool for automated alignment trimming in large-scale phylogenetic analyses. Bioinformatics 2009, 25(15):1972-1973.

74. Lartillot N, Lepage T, Blanquart S: PhyloBayes 3: a Bayesian software package for phylogenetic reconstruction and molecular dating. Bioinformatics 2009, 25(17):2286-2288.

75. Felsenstein J: PHYLIP - phylogeny inference package (version 3.2). Cladistics 1989, 5(2):164-166.

76. Stamatakis A: RAxML-VI-HPC: maximum likelihood-based phylogenetic analyses with thousands of taxa and mixed models. Bioinformatics 2006, 22(21):2688-2690.

77. Lemieux C, Otis C, Turmel M: Data from: Six newly sequenced chloroplast genomes from prasinophyte green algae provide insights into the relationships among prasinophyte lineages and the diversity of streamlined genome architecture in picoplanktonic species. In TreeBase repository; http://purl.org/phylo/treebase/phylows/study/TB2:S16332.

doi:10.1186/1471-2164-15-857

Cite this article as: Lemieux et al: Six newly sequenced chloroplast genomes from prasinophyte green algae provide insights into the relationships among prasinophyte lineages and the diversity of streamlined genome architecture in picoplanktonic species. BMC Genomics 2014 15:857.

\section{Submit your next manuscript to BioMed Central and take full advantage of:}

- Convenient online submission

- Thorough peer review

- No space constraints or color figure charges

- Immediate publication on acceptance

- Inclusion in PubMed, CAS, Scopus and Google Scholar

- Research which is freely available for redistribution 